\title{
Análise Estatística de Expressão Gência por SAGE \\ (Serial Analysis of Gene Expression)
}

Ricardo Zorzetto Nicoliello Vêncio

\author{
Dissertação apresentada \\ ao \\ Instituto de Matemática e Estatística \\ da \\ Universidade de São Paulo \\ para a obtenção do grau de \\ Mestre em Estatística \\ Área de Concentração: Estatística \\ Orientador: Prof. Dr. Carlos Alberto de Bragança Pereira
}

São Paulo - Setembro - 2004 
ANÁLISE ESTATÍSTICA DE EXPRESSÃO GÊNICA POR SAGE (SERIAL ANALYSIS OF GENE EXPRESSION)

Este exemplar corresponde à redaçāo final da dissertação devidamente corrigida e defendida por Ricardo Zorzetto Nicoliello Vêncio e aprovada pela comissão julgadora.

São Paulo, 15 de setembro de 2004

Banca Examinadora:

Prof. Dr. Carlos Alberto de Bragança Pereira (orientador) - MAE - IME - USP

Prof. Dr. Júnior Barrera - MAC - IME - USP

Prof. Dr. Wilson Araújo da Silva Júnior - DG - FMRP - USP 


\section{Resumo}

No presente trabalho fizemos uma revisão bibliográfica sobre os principais métodos estatísticos utilizados atualmente para a análise de dados de expressão gênica obtidos pela técnica de Biologia Molecular conhecida como SAGE - Serial Analysis of Gene Expression, ou Análise Serial de Expressão Gênica (Velculescu et al., 1995) (www.vision.ime.usp.br/ rvencio/Mestrado). Além de dar o panorama do estado-da-arte na área, apresentamos dois métodos originais desenvolvidos neste Projeto de Mestrado: SAGEci (www.vision.ime.usp.br/ rvencio/SAGEci), para construção de intervalos de credibilidade para razões de expressão (Vêncio et al., 2003); e SAGEßBin (www.vision.ime.usp.br/ rvencio/SAGEbetaBin), para incorporação da variabilidade biológica intrínseca às bibliotecas na identificação de genes diferencialmente expressos por meio de misturas (Vêncio et al., 2004).

\section{Abstract}

In this work we carried out a bibliographic review on the main statistical methods used nowadays to analyze gene expression data obtained by a Molecular Biology technique known as SAGE - Serial Analysis of Gene Expression (Velculescu et al., 1995) (www.vision.ime.usp.br/ rvencio/Mestrado). Along with the field's state-of-art, we presented two original methods developed in this Msc. Project: SAGEci, for the construction of credibility intervals to expression ratios (Vêncio et al., 2003); and SAGEßBin, to accounting for libraries' intrinsic designed biological variability when identifying differentially expressed genes by means of mixture models (Vêncio et al., 2004). 
Índice

Capítulo pág.

Agradecimentos

1 - Introdução

2 - Contexto da Biologia e Bioinformática 7

2.1 - Introdução à Expressão Gênica $\quad 7$

2.2 - SAGE

3 - Estimação 14

3.1 - Estimação Pontual 15

3.2 - Estimação por Intervalo $\quad 21$

4 - Detecção de Expressão Diferencial 25

4.1 - Bibliotecas Únicas ou "Pseudo-bibliotecas" 26

4.2 - Bibliotecas com Réplicas Biológicas 31

4.3 - Múltiplas Bibliotecas 38

5 - Aplicação à Dados Reais 40

6 - Conclusões 45

$\begin{array}{ll}\text { Bibliografia } & 47\end{array}$ 


\section{Agradecimentos}

$\mathrm{O}$ autor recebeu apoio financeiro da FAPESP (Fundação de Amparo à Pesquisa do Estado de São Paulo) durante todo o Projeto de Mestrado: FAPESP 02/04698-8.

Agradeço muito à médica Dra. Helena P. Brentani (Hospital do Câncer A.C. Camargo, São Paulo) e ou físico Diogo F.C. Patrão (Ludwig Institute for Cancer Research, São Paulo) pela colaboração científica neste trabalho. Juntamente com meu orientador, Prof. Dr. Carlos A. B. Pereira, fazem parte do grupo, muitas vezes mencionado durante esta Dissertação, que de fato desenvolveu todas as técnicas originais apresentadas aqui. Sem a ajuda de todos eles, este Projeto de Mestrado certamente não teria sido tão divertido e produtivo (vai!). 


\section{Capítulo 1}

\section{Introdução}

O objetivo desta Dissertação de Mestrado é apresentar uma visão geral e revisar o estado-da-arte dos métodos estatísticos aplicados ao estudo da Expressão Gênica, em particular através da técnica de SAGE - Serial Analysis of Gene Expression, ou numa tentativa de tradução para o português, Análise Serial de Expressão Gênica (Velculescu et al., 1995).

O Capítulo 2 introduz brevemente a técnica de SAGE do ponto de vista da Biologia e da Bioinformática. Apresenta e caracteriza o tipo de dado que deve ser analisado. Os capítulos seguintes abordam a técnica do ponto de vista do estatístico.

Os métodos foram divididos nas principais tarefas da Estatística: estimação de parâmetros e detecção de expressão diferencial. Essa divisão corresponde à principal divisão conceitual da Estatística: Estimação e Teste de Hipóteses.

O Capítulo 3 foi dividido em Estimação Pontual e Estimação por Intervalo. O objetivo é mostrar como encontrar valores numéricos para quantidades desconhecidas e determinar "barras-de-erro" para as mesmas.

O Capítulo 4, que trata da detecção de expressão diferencial, foi dividido em métodos para:

- comparações entre duas classes, utilizando apenas uma biblioteca SAGE em cada classe ou utilizando diversas bibliotecas agregadas numa única "pseudo-biblioteca" em cada classe;

- comparações entre duas classes, utilizando as réplicas biológicas individualmente dentro de cada classe;

- detecção de valores discrepantes (outliers) num único grande grupo contendo várias bibliotecas.

O Capítulo 5 traz um exemplo de aplicação do método que estamos desenvolvendo, enfatizando suas vantagens frente aos métodos conhecidos pela comunidade usuária de SAGE. A descrição desse novo método está apresentada em adição aos outros métodos, obedecendo ao objetivo desta Dissertação de ser um trabalho de revisão. Porém, o novo método é apresentado de uma forma mais elaborada, em um nível de detalhe maior que os outros disponíveis.

O Capítulo 6 apresenta as conclusões deste trabalho. 
Muitos dos métodos apresentados não são específicos à técnica de SAGE, mas podem ser aplicados a outros dados do tipo contagem/freqüência em Biologia, como por exemplo contagem de EST Expressed Sequence Tags, também conhecido como "Digital Northern", ou MPSS - Massively Parallel Signature Sequencing (Brenner et al., 2000).

Alguns dos métodos discutidos foram implementados através de programas, ou mais precisamente scripts, na liguagem estatística $\mathrm{R}$ (Ihaka \& Gentleman, 1996; http://www.r-project.org) e estão disponíveis, gratuitamente, bastando uma simples requisição ao autor: rvencioevision. ime.usp.br. 


\section{Capítulo 2}

\section{Contexto da Biologia e Bioinformática}

Antes de discutir os aspectos estatísticos da técnica de SAGE, é importante contextualizar seu papel no cenário da Biologia Molecular. Além disso, alguns aspectos de Bioinformática do processo devem ser discutidos, para que se tenha absolutamente clara a natureza dos dados que serão tratados tão exaustivamente nas seções seguintes. É fundamental se compreender como esses dados de contagem são obtidos e quais são as hipóteses subjacentes na medição do fenômeno biológico Expressão Gênica.

\subsection{Introdução à Expressão Gênica}

O ácido desoxirribonucleico, DNA, é considerado a molécula fundamental da maioria dos seres vivos (existem vírus em que esse papel é feito por outra molécula). É o DNA que contém todas as informações genéticas de cada indivíduo, e que tem a capacidade de transmiti-las à sua descendência. É uma molécula grande, formada por repetições de apenas quatro unidades básicas. O biólogo James Watson e o físico Francis Crick publicaram (Watson \& Crick, 1953) uma descrição da molécula e foram os primeiros a sugerir seu mecanismo de replicação, marcando profundamente a história da Biologia.

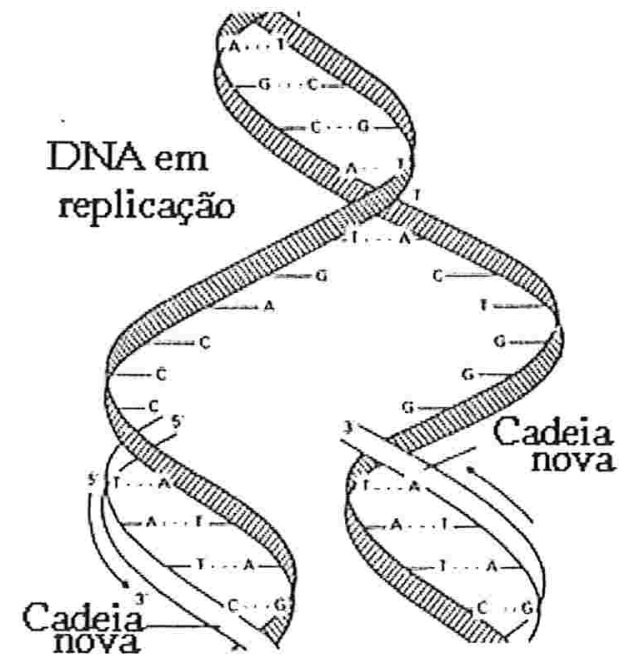

Fig. 1 - Esquema de uma dupla-fita de DNA sendo replicada. O pareamento específico das bases A com T e C com Gé a propriedade mais importante da molécula de DNA 
As quatro unidades básicas do DNA são os nucleotídeos: Adenina (A), Citosina(C), Guanina (G) e Timina (T). O DNA é formado por uma fita de nucleotídeos, ligados em ordens diversas e outra fita complementar, com nucletídeos que se "encaixam" na outra fita: A com T e C com G. Essas duplas formadas são chamadas pares de bases (Fig. 1).

O DNA tem duas funções básicas: Replicação, responsável pela hereditariedade; e Transcrição de genes, para fornecer mensagens. O RNA resultante pode ser de três tipos: mRNA (mensageiro), rRNA (ribossômico) e tRNA (transportador). Juntos, eles realizam a Tradução, que dá como produto final um polipeptídeo de cada gene. Os polipeptídeos podem ser proteínas ou parte delas, e são a parte ativa e funcional da célula.

Desde meados da década de 50 já se pensava na hipótese do DNA constituir-se num molde para a síntese de moléculas de RNA, as quais, por sua vez, devido a sua mobilidade e flexibilidade acoplariam aos ribossomos e dirigiriam a síntese de proteínas. Baseado neste raciocínio, o físico F. Crick propôs em 1956 o modelo chamado Dogma Central da Biologia, salientando o fluxo unidirecional da informação: do DNA à proteína (Fig. 2).

Para compreender este fluxo utilizamos a idéia de moldes. O DNA serviria de molde para a síntese de novas moléculas de DNA (duplicação) e, ao mesmo tempo, para a síntese de moléculas de RNA (transcrição). Por outro lado algumas destas moléculas de RNA, que denominamos RNA mensageiros (mRNA), poderiam servir de molde para a síntese de proteínas (tradução), que ocorre nos ribossomos. Esta

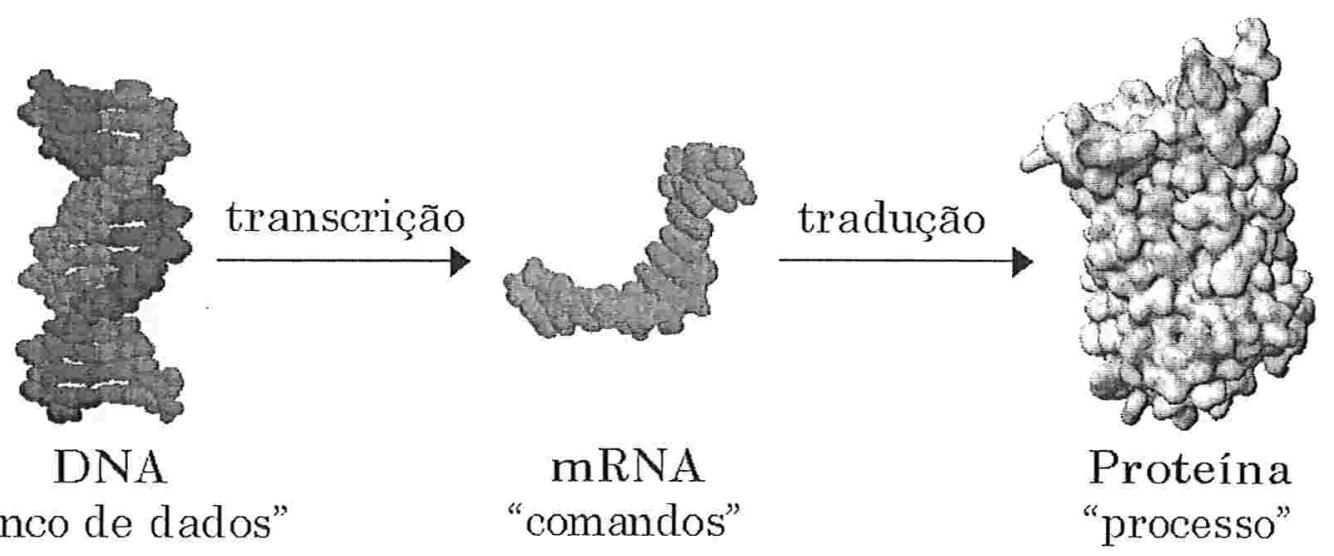

Fig. 2 - Esquema do Dogma Central da Biologia. Analogamente ao funcionamento de um computador, o DNA tem função de banco de dados, contendo toda a informação; os mRNAs são análogos aos comandos, pois codificam as mensagens de ação contidas em princípio no DNA e as proteínas são análogas aos processos que de fato realizam as tarefas (figura sem escala). 
hipótese tem sido confirmada até hoje. Entretanto, a proposta original foi ampliada nos últimos anos com a descoberta da enzima transcriptase reversa. Estes novos conhecimentos permitiram que o Dogma Central se ampliasse sem, contudo, perder a unidirecionalidade.

O objetivo de todas as técnicas de análise de Expressão Gênica é sempre interceptar a etapa de transcrição, estudando os "comandos" ativos nos organismos em diferentes estados biológicos. As principais técnicas modernas utilizadas para análise em larga-escala são o SAGE e o microarray. Neste trabalho iremos tratar da primeira técnica.

\subsection{SAGE}

A técnica de SAGE, descrita por Velculescu et al. (1995), baseia-se no isolamento de segmentos de seqüências únicas de cada transcrito, isto é, um gene sendo expresso. O SAGE conta os transcritos através do seqüenciamento de pequenas seqüências identificadoras, as tags, também conhecidas pelos nomes de etiquetas, marcas, marcadores, assinaturas, etc (Fig. 3).

Existe uma convenção para definir a orientação de uma molécula de mRNA que é lê-la a partir da extremidade $5^{\prime}$ em direção à extremidade 3'. Em geral os transcritos de seres eucariotos possuem também uma característica conhecida como cauda de poly-A, isto é, uma seqüência repetida de mais de 8 bases $A$, que por sua vez permite determinar a orientação do transcrito pois a extremidade 3 ' é a extremidade onde encontra-se a cauda poly-A.

Dada a seqüência orientada $5^{\prime}-3^{\prime}$ de um transcrito, seu tag identificador está bem definido: as 10 bases variáveis características do transcrito adjacentes às 4 bases da subseqüência CATG posicionada mais próxima da extremidade $3^{\prime}$.

A subseqüência CATG é o sítio de clivagem da enzima NlaIII, utilizada no processo para "cortar" os transcritos. Alguns genes podem simplesmente não possuir esse sítio de clivagem e portanto não são observáveis por esta técnica. Existem variações do protocolo original utilizando outras enzimas de restrição diferentes da NlaIII que, portanto, utilizam outras definições de tag, já que a subseqüência CATG é característica daquela enzima. Utilizando outras enzimas no processo, genes cujos transcritos não possuem o sítio CATG também podem ser observados. 
Depois de "cortados" os tags das seqüências originais, eles são concatenados em ditags e posteriormente todos os ditags são concatenados em longas moléculas de DNA artificiais. Essas longas moléculas são seqüenciadas como usual (Fig. 3).

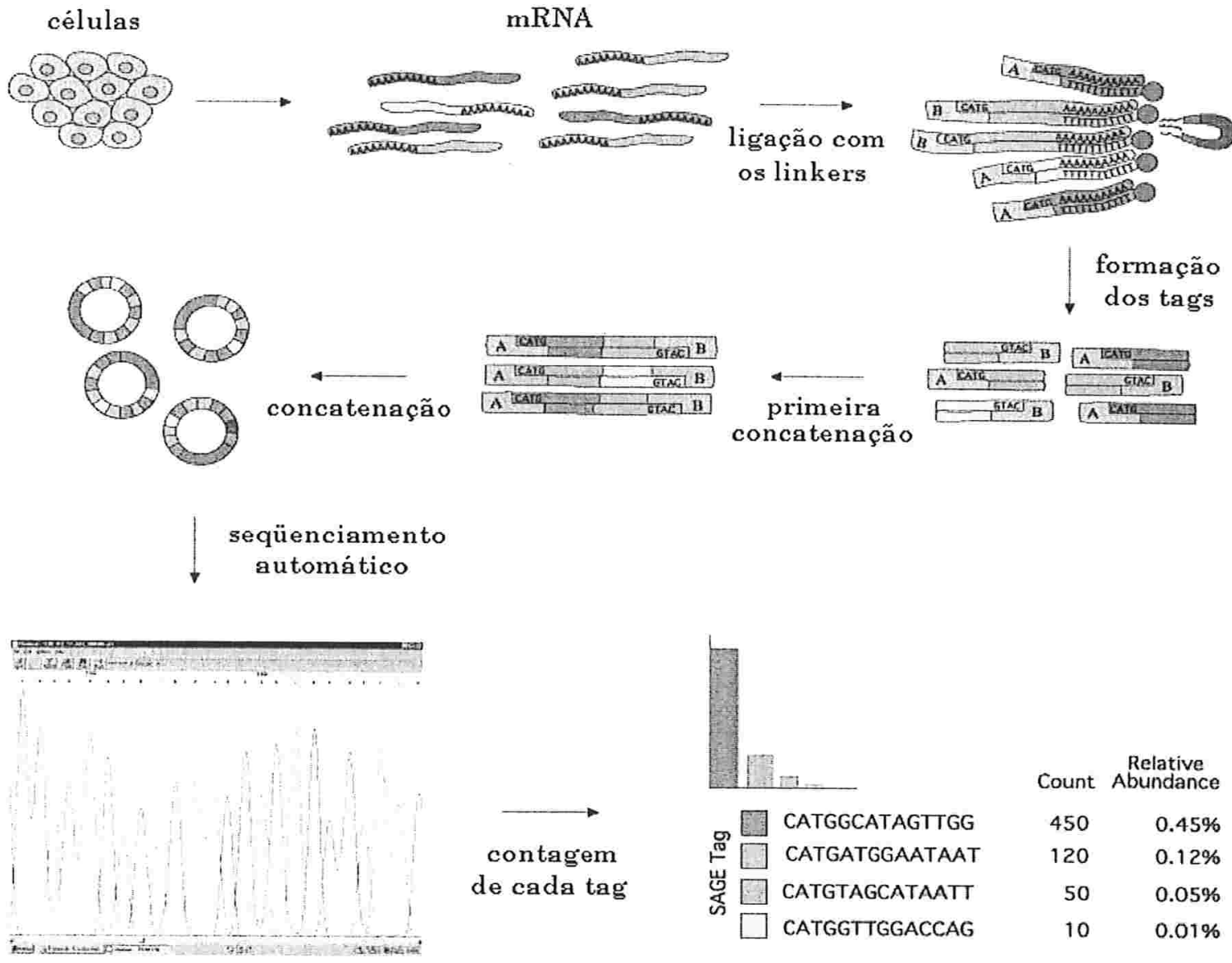

Fig. 3 - Fluxo das atividades experimentais em SAGE.

Adaptado de: http://sciencepark.mdanderson.org/ggeg/SAGE_technique.htm

As contagens dos transcritos são extraídas dos resultados das máquinas automáticas de seqüenciamento usando softwares específicos. Os passos são os seguintes (Lash et al., 2000): 
1. localização dos sítios NlaIII (ou seja, os "sinais de pontuação" CATG) dentro de um ditag (primeira concatenação na Fig. 3)

2. extrair os ditags de $20-26$ bases de comprimento que estão entre dois desses "sinais de pontuação";

3. remover ocorrências repetidas dentro de um ditag;

4. definir duas tags como as primeiras e últimas 10 bases de cada ditag, fazendo o complemento-reverso da seqüência quando for necessário para apresentá-la na orientação 5'-3';

5. remover tags correspondentes aos linkers (TCCCCGTACA e TCCCTATTAA) bem como tags com bases não especificadas (outras que não $A, C, G$ e T);

6. contar o número de ocorrências de cada tag.

É importante ter em mente que essa tecnologia fornece a contagem de um dado transcrito, apresentada como a fração relativa ao total de transcritos observados, e não um resultado relativo à outro experimento ou a um gene housekeeping particular, como acontece nas técnicas baseadas em hibridização. Isso é uma vantagem pois evita processos sujeitos a erros como a de normalização entre experimentos. Outra vantagem é que o SAGE determina os níveis de expressão diretamente das amostras de mRNA, não sendo necessário dispor de fragmentos gene-específicos de DNA imobilizados para medir cada gene, como é necessário nas técnicas baseadas em hibridização. É por isso que o SAGE é chamado de "um sistema aberto", justificando a analogia que diz que é o "Linux da genômica funcional" (SAGE2000 Conference, September 2000).

O mapeamento entre a tag e seu gene é um importante problema de Bioinformática já que nos permite dar sentido biológico aos resultados ao identificar a tag. Esse mapeamento é feito orientando as seqüências acumuladas no banco-de-dados público GenBank (http://www.ncbi.nih.gov/Genbank), usando o sinal de poliadenilação (ATTAAA ou AATAAA), a cauda de poly-A (mínimo de 8 As contíguos) e a anotação de orientação (3' ou $\left.5^{\prime}\right)$.

As tags dos genes são ligadas a um identificador de UniGene cluster. O UniGene é um sistema automático de particionamento das seqüências de do banco-de-dados GeneBank, incluindo ESTs, em conjuntos de clusters não-redundantes. Teoricamente, cada UniGene cluster contêm seqüências que representam um único gene (Schuler, 1997).

Ao definir as tags, 5 "classes" arbitrárias de confiabilidade são identificadas, em ordem crescente de confiabilidade, para as associações tag-UniGene: 
1. obtidas de seqüências de mRNAs ou cDNA de genes bem conhecidos e caracterizados;

2. obtidas de seqüências de EST com sinal de poliadenilação e/ou cauda de poliadenilação anotadas como seqüências 3';

3. obtidas de seqüências de EST com sinal de poliadenilação e/ou cauda de poliadenilação mas sem anotação $3^{\prime}$ ou $5^{\prime}$;

4. obtidas de seqüências de EST com sinal de poliadenilação e/ou cauda de poliadenilação anotadas como seqüências 5';

5. obtidas de seqüências de EST sem sinal de poliadenilação e/ou cauda de poliadenilação mas anotadas como tendo orientação 3'.

Para cada tag, outros dois parâmetros de qualidade são calculados: (i) a freqüência de uma associação gene-tag, e (ii) a freqüência de uma associação tag-gene.

O projeto The Cancer Genome Anathomy Project SAGE Project (http://cgap.nci.nih.gov), tornou disponíveis novas ferramentas de Bioinformática que conseguem levar em consideração essas medidas de confiança nas associações tag-gene. Esse esforço resultou na interface web SAGE Genie (http://cgap.nci.nih.gov/SAGE) (Boon et al., 2002). Uma novidade importante é que essa interface consegue trabalhar com transcritos alternativos (alternative splicing), tags redundantes, priming interno, etc.

Idealmente, as tags são longas o suficiente para definir univocamente um transcrito, e a abundância de uma tag é proporcional ao nível de expressão do transcrito na mistura original de RNA. Entretanto, o SAGE é um método de amostragem, o que resulta em algumas dificuldades, como por exemplo: alguns transcritos presentes em baixa abundância podem não ser vistos ou o número de contagens pode não refletir acuradamente sua verdadeira abundância nas células devido a erros sistemáticos ou de seleção (Margulies et al., 2001). Além desses erros de amostragem existem os erros de seqüenciamento, a possibilidade de tags não unívocas, ou ainda transcritos que não geram tags utilizando uma dada enzima. É interessante notar que em torno de $30 \%$ dos transcritos, cuja seqüência é conhecida completamente (full length), contém seqüências repetitivas dentro de suas seqüências. SAGE tags definidas dentro desses elementos repetitivos serão contadas muitas vezes para diferentes transcritos, pois muitos genes expressam aquela tag. A identificação do gene associado à uma tag desse tipo é praticamente impossível com os métodos conhecidos atualmente. 
Esses problemas técnicos poderão ser vencidos no futuro com o aumento do número de tags coletadas, o uso de tags mais longas (maiores que 10 bases) e o uso de diferentes enzimas de restrição. 


\section{Capítulo 3}

\section{Estimação}

O objetivo do processo de Estimação é obter valores numéricos para quantidades desconhecidas numa amostra ou numa população. A estimação é, ao lado do teste de hipóteses, uma tarefa fundamental da Estatística e é dividida em Estimação Pontual e Estimação por Intervalo.

A Estimação Pontual atribui para uma quantidade desconhecida a melhor adivinhação científica possível. $\mathrm{Na}$ abordagem Freqüentista da Estatística o "melhor" estimador tem certas propriedades como, por exemplo, ser não-viciado. Os Bayesianos discordam radicalmente deste conceito, uma vez que seus estimadores sempre são viciados pelo conhecimento a priori. Portanto, "melhor" é um conceito relativo e passível de definição.

A Estimação por Intervalo pretende encontrar intervalos numéricos que contenham a quantidade desconhecida em questão e atribuir algum tipo de probabilidade para este fato. Novamente, um intervalo é visto com interpretações bem diferentes dependendo da abordagem utilizada, Freqüentista ou Bayesiana.

$\mathrm{Na}$ visão Freqüentista, obter um intervalo de $\alpha \%$ de confiança, significa somente aplicar um procedimento de cálculo aos dados que produz um intervalo. Este procedimento alega que os intervalos calculados, aplicados à dados virtuais, deverão conter o verdadeiro (e desconhecido) valor do parâmetro em questão em pelo menos $\alpha \%$ das vezes que o utilizarmos. Esses dados virtuais são as amostras aleatórias e assume-se que são gerados pela mesma função de densidade de probabilidade (fdp) que gerou os dados observados. Isso não significa que a probabilidade do valor verdadeiro do parâmetro estar no intervalo construído é $\alpha$. Na abordagem Freqüentista o valor verdadeiro é um número e não uma variável aleatória, não permitindo esse tipo de afirmação probabilística. Entretanto, esse desejado tipo de afirmação é possível quando utiliza-se a abordagem Bayesiana. Os Bayesianos não acreditam no conceito de "dados que podiam ter sido observados mas não foram" (dados virtuais) e baseiam suas conclusões na fdp $a$ posteriori dos parâmetros. A probabilidade de que o parâmetro se encontre dentro de um certo intervalo pode ser calculada para qualquer intervalo numérico. Para harmonizar com a noção intuitiva de barra-de- 
erro, utiliza-se o menor intervalo em torno da moda da fdp a posteriori que integra $\alpha$ de probabilidade. Esse é o intervalo de credibilidade Bayesiano.

\subsection{Estimação Pontual}

As principais tarefas da Estimação Pontual no contexto de SAGE são as estimações de: taxa de erro no processo de seqüenciamento, contagens das tags e abundância das tags (também conhecida por contagens normalizadas, proporções, concentrações, etc).

Uma questão também importante, mas que não será abordada neste trabalho por ser bastante complicada, é a estimação do tamanho de um transcriptoma e sua distribuição. Isto é, descobrir quantos transcritos diferentes estão sendo expressos numa dada condição celular e como estão distribuídos entre os níveis de expressão. Mesmo assim, é importante ter em mente que essa distribuição é bastante desequilibrada em direção ao zero, isto é, existem muitos transcritos com pequena abundância e poucos transcritos bastante abundantes. Os trabalhos de Stollberg et al. (2000) e Stern et al. (2003) mostraram, usando experimentos simulados, a impossibilidade de resolução dos problemas de caracterização completa do transcriptoma com bibliotecas SAGE possuindo o tamanho das bibliotecas construídas usualmente. Talvez esses problemas possam ser resolvidos num futuro próximo com a utilização de tecnologias alternativas como MPSS - Massively Parallel Signature Sequencing (Brenner et al., 2000) que tem uma capacidade de seqüenciamento muito maior que o SAGE.

No que segue, iremos discutir a estimação das taxas de erro de seqüenciamento, a primeira questão a ser considerada na análise estatística de SAGE.

É possível imaginar que as contagens das tags estão claramente definidas como dado de saída das máquinas de seqüenciamento automático e que é suficiente contar as seqüências identificadas nos cromatogramas. Entretanto, o seqüenciamento de SAGE é, por si só, sujeito a processos estocásticos como erros na amplificação pela enzima ou erros na leitura das bases (base miscalling). Portanto, o resultado de uma tag pode ser modelado e estimado. A estimação dessas taxas de erro é uma questão relevante, mesmo que não seja utilizada em processos posteriores de correção. 
O número de erros de seqüenciamento numa tag de 10 bases, assumindo erros de leitura eqüiprovaveis e independentes da posição dentro da seqüência, segue uma distribuição $\operatorname{Binomial}(10, \varepsilon)$ onde $\varepsilon$ é a taxa de erro expressa em unidades de erros por base. Os números relevantes são $\mathbf{P}$ (somente 1 erro $)=10 \cdot \varepsilon^{1}(1-\varepsilon)^{9}, \mathbf{P}($ erros $\geq 1)=1-(1-\varepsilon)^{10}$ e $\mathbf{P}($ erros $\geq 2)=\mathbf{P}($ erros $\geq 1)$ - $\mathbf{P}$ (somente 1 erro).

A primeira estimativa para $\varepsilon$ foi proposta no trabalho seminal de Velculescu et al. (1997) onde compararam seus resultados de SAGE com o genoma completo da levedura. Eles encontraram $\varepsilon \cong 0.007$ ou $\mathbf{P}$ (erros $\geq 1) \cong 0.068$. O uso da aproximação de $1 \%$ para a taxa de erro, importada dos projetos de seqüenciamento de genomas e EST, é bastante comum na análise de SAGE porque corresponde ao amplamente utilizado valor de corte score 20 , no conhecido software de análise de cromatogramas phred (Ewing \& Green, 1998).

Colinge \& Feger (2001) trabalharam com $\varepsilon=0.01$ e portanto $\mathbf{P}$ (erros $\geq 1)=0.096 \gg \mathbf{P}($ erros $\geq 2)=0.004$. Esse fato sugere que a maioria dos erros de seqüenciamento devem ser uma mudança de uma única base. Uma tag pode ter vizinhos devido a substituição, inserção ou deleção, isto é, tags que diferem umas das outras somente por uma aplicação destas operações de edição. Estes autores construíram uma matriz de transição com cada elemento $\{P\}_{i k}=p(j \mid k)$ definido como sendo a probabilidade da $k$-th tag observada ser contada como a $j$-th tag observada devido apenas a 1 erro de substituição. É interessante notar que uma tag rara sem vizinhos imediatos tem $p(j \mid j)=1$, mesmo que $\mathbf{P}($ nenhum erro $)=(1-\varepsilon)^{10}=0.904$. Uma aproximação mais refinada deveria considerar os erros de inserção e deleção no caminho da tag $k$ para a $\operatorname{tag} j$ :

$$
\begin{aligned}
p(j \mid k)=\mathbf{P}(j \leftarrow k)= & \mathbf{P}(I)+\mathbf{P}(D)+\mathbf{P}(S) \\
& -\mathbf{P}(I) \mathbf{P}(D)-\mathbf{P}(I) \mathbf{P}(S)-\mathbf{P}(D) \mathbf{P}(S) \\
& +\mathbf{P}(I) \mathbf{P}(D) \mathbf{P}(S)
\end{aligned}
$$

onde $I, D$ ou $S$ são as transições $\{j \leftarrow k\}$ devido a erros únicos de inserção, deleção ou substituição, respectivamente.

Recentemente, Blades et al. (2004) criaram um procedimento simples para estimar essas taxas de erro de primeira ordem de cada biblioteca. Estes autores chamaram de sombras (shadows) as tags geradas por artefatos do processo de medida. Finalmente, escreveram as taxas de erro como o aumento das contagens de shadows, obtidas pelo incremento das contagens verdadeiras $x$ : 
$\varepsilon=\frac{\Delta s}{\Delta x}=\frac{\Delta s}{\Delta y+\Delta s}=\frac{1}{(\Delta s / \Delta y)^{-1}+1}=\frac{1}{\theta^{-1}+1}$

onde $y$ são as contagens efetivamente observadas de uma dada tag.

Se todos os vizinhos fossem shadows, seria possível de estimar $\theta$ como o coeficiente angular de uma regressão usual no espaço: contagens observadas us. contagens dos vizinhos. Entretanto, isso não é verdade, portanto precisamos identificar nesse espaço um subconjunto de pontos $\left(y_{j}, s_{j}\right)$ para os quais essa hipótese parece razoável. Devido a forma altamente distorcida, em direção dos transcritos raros do transcriptoma, é de se esperar que a tendência linear seja visível somente na região do espaço que representa tags bastante abundantes, isto é, os maiores pontos $y_{j}$. Ainda, espera-se que a taxa de erro seja relativamente pequena, manifestando-se por uma reta de regressão próxima à uma linha horizontal.

Para usar todos os pontos $\left(y_{j}, s_{j}\right)$ sem escolher manualmente é necessário utilizar-se técnicas de regressão robustas, já que existe muita superposição com pares $\left(y_{j}, s_{j}\right)$ para os quais vários vizinhos não-artefatos existem. Blades et al. (2004) indicaram que a regressão robusta tem

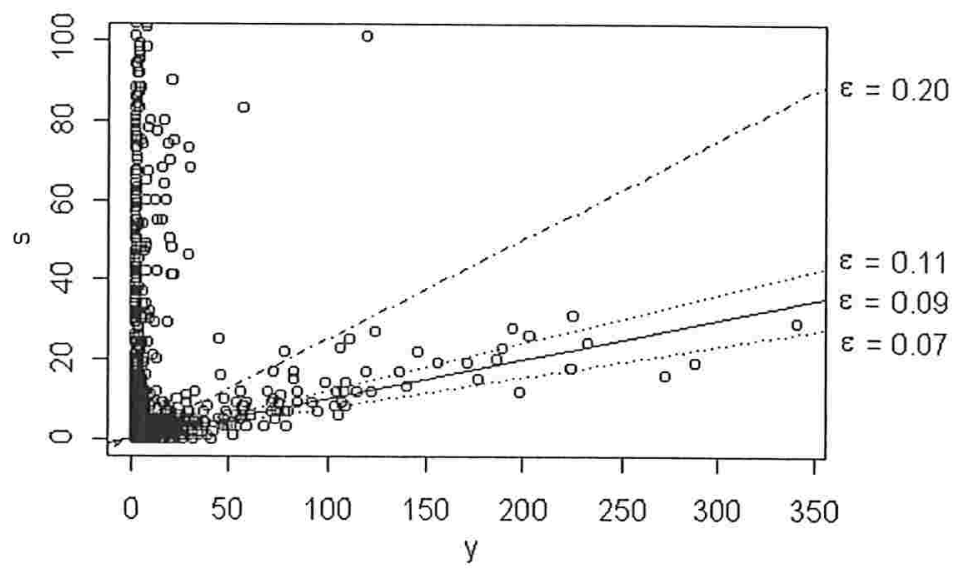

Fig. 4 - Estimação da taxa de erro de substituição para a bilbioteca pancreatica normal HX (cód. de acesso GSM721 no banco-de-dados GEO).

desempenho superior à regressão linear usual ou a regressão resistente.

A Fig. 4 mostra uma ilustração deste método de estimação para uma das bibliotecas utilizadas no trabalho original, a biblioteca HX de pâncreas normal (cód. de acesso no banco-de-dados Gene Expression 
Omnibus GEO: GSM721). Usando a regressão linear robusta eles encontraram uma taxa de erro de substituição $\varepsilon=0.09$, com intervalo de $95 \%$ de confiança $[0.07 ; 0.11]$. A linha correspondente a uma taxa de erro de $20 \%$ também é mostrada apenas para ilustração.

No que se segue iremos discutir o segundo problema importante na análise estatística de SAGE, a estimação das contagens.

É possível desconfiar que algumas das ocorrências de tags raras não são reais, mas sim resultado de erros experimentais. Um exemplo claro poderia ser uma tag abundante que, sofrendo uma mudança errônea na sua seqüência de 10 bases, gera uma tag única não existente ou "infla" as contagens de outra tag existente.

Colinge \& Feger (2001) propuseram um método de estimação das contagens que leva em consideração os erros de seqüenciamento. Eles aproximaram o efeito das taxas de erro para contagens médias esperadas e construíram um sistema linear de equações:

$\left\{\begin{array}{c}y_{1}=p(1 \mid 1) x_{1}+\cdots+p(1 \mid t) x_{t} \\ \vdots \\ y_{\iota}=p(t \mid 1) x_{1}+\cdots+p(t \mid t) x_{t}\end{array} \Rightarrow \mathbf{x}=\left[\begin{array}{ccc}p(1 \mid 1) & \ldots & p(1 \mid t) \\ \vdots & \ddots & \vdots \\ p(t \mid 1) & \cdots & p(t \mid t)\end{array}\right]^{-1} \mathbf{y} \quad\right.$ (Eq.3)

onde $t$ é o número de tags únicas observadas, $p(j \mid k)$ é a probabilidade de que a $k$-ésima tag observada seja contada como a $j$-ésima tag observada devido a apenas 1 erro de substituição, $\mathbf{x}$ são as verdadeiras e desconhecidas contagens e y são as contagens observadas. Por primeiraordem entende-se que apenas os principais efeitos são considerados, isto é, $p(j \mid k)=\mathbf{P}(j \leftarrow k) \leq \mathbf{P}(j \leftarrow \ldots \leftarrow k)$, onde as setas denotam uma operação de edição na seqüência devido a um erro.

Apesar da validade da propriedade fundamental $\Sigma x .=m=\Sigma y$., a aproximação deles força a impossível continuidade das contagens, isto é, $y_{j} \in\{0,1, \ldots, m\}$ mas as soluções deles $x_{j} \in \Re$. Akmaev \& Wang (2004) criticaram esse fato, alertando para a falta de interpretabilidade das estimativas das "verdadeiras contagens", principalmente quando a estimação produz valores negativos. Este tipo de problema é chamado pelos Cientistas da Computação como um problema de Programação Inteira e lidar com ele, como se fosse um problema contínuo de Programação Linear ou mesmo um problema simples de Álgebra Linear, é sabidamente uma abordagem inapropriada. Entretanto o trabalho desses autores é conhecido e citado na comunidade SAGE apesar de ser conceitualmente equivocado.

Uma possível e conceitualmente correta formulação para abordar a estimação das contagens poderia ser: 


$$
\begin{aligned}
& \left\{\begin{array}{c}
y_{1}=\left[p(1 \mid 1) x_{1}\right]+\cdots+\left[p(1 \mid t) x_{t}\right] \\
\vdots \\
y_{t}=\left[p(t \mid 1) x_{1}\right]+\cdots+\left[p(t \mid t) x_{t}\right]
\end{array} \Rightarrow\right. \\
& \mathbf{x}=\arg _{\mathrm{u}}\left(\min _{\Theta}\left(\sum_{j=1}^{t}\left|\sum_{k=1}^{t}\left[p(j \mid k) u_{k}\right]-u_{j}\right|\right)\right)
\end{aligned}
$$

onde $\Theta=\left\{\left(x_{1}, \ldots, x_{t}\right): x_{j} \in Z_{+}, \Sigma x .=m\right\}$ e [.] é a aproximação usual de reais para inteiros (teto ou chão dependendo de qual é mais próximo).

A restrição imposta por $\Theta$ torna o problema muito mais difícil e solução ainda é inexistente na comunidade SAGE.

Akmaev \& Wang (2004) desenvolveram uma alternativa ao método de Colinge \& Feger (2001) para corrigir erros de seqüenciamento. Eles usaram uma abordagem heurística em múltiplos passos, bastante ligada à mecânica do processo de SAGE, que preserva a natureza discreta dos dados e utiliza informação dos cromatogramas e dos phred scores (Ewing \& Green, 1998). A análise estatística é simples e é apenas um dos passos do algoritmo de Bioinformática proposto em Akmaev \& Wang (2004) e disponível através do software comercial SAGEScreen (Genzyme Inc.).

É importante notar que a correção de potenciais erros de seqüenciamento ao nível das contagens ou técnicas como denoising (Blades et al., 2004b) são abordagens promissoras, mas ainda não estão amplamente difundidas como procedimentos de rotina na análise de dados de SAGE.

No que segue iremos abordar a estimação da abundância, o mais importante problema de estimação pontual na análise estatística de SAGE.

À primeira vista, o problema de estimar a abundância $\pi \in[0 ; 1]$ de uma tag poderia ser considerado como um desinteressante e fácil problema: $p=x / m$, onde $x$ é o número de contagens (pré-processado ou não) de uma dada tag, $m$ é o total de tags seqüenciadas na biblioteca e $p$ é a estimativa de $\pi$. Entretanto, outras opções elaboradas existem.

Na realidade, $p$ é o estimador de Máxima Verosimilhança (MV) de um Processo de Bernoulli. Os modelos de Bernoulli ou Poisson, e não o modelo Hipergeométrico por exemplo, são amplamente utilizados para modelar dados de contagem de expressão gênica porque a aproximação de amostra proveniente de uma população infinita é apropriada (com certeza, $m$ é muito menor que o total de moléculas de mRNA coletadas nas células). 
$\mathrm{Na}$ abordagem Bayesiana, todos os parâmetros ou quantidades desconhecidas são variáveis aleatórias e o conhecimento prévio sobre eles é quantificado por meio das fdps a priori. Supondo que o Processo de Bernoulli é uma boa descrição dos dados de SAGE, então utilizando uma análise Bayesiana elementar:

$$
\begin{aligned}
\left\{\begin{array}{l}
h(\pi) \propto(1-\pi)^{\beta-1} \pi^{\alpha-1} \\
L(x \mid \pi) \propto(1-\pi)^{m-x} \pi^{x}
\end{array} \Rightarrow h(\pi \mid x)\right. & =\frac{f(\pi) L(x \mid \pi)}{\int_{0}^{1} f\left(\pi^{\prime}\right) L\left(x \mid \pi^{\prime}\right) d \pi^{\prime}} \\
& =\frac{(1-\pi)^{m-x+\beta-1} \pi^{x+\alpha-1}}{B(x+\alpha, m-x+\beta)}
\end{aligned}
$$

onde $\alpha>0$ e $\beta>0$ são os parâmetros que definem a fdp a priori Beta, $x$ é o número de contagens para uma dada tag, $m$ é o total de tags seqüenciadas, $\pi$ é a abundância da $\operatorname{tag}, L(\cdot)$ é a função de verosimilhança e $B($ ) é a função especial beta. A Beta é a escolha padrão de fdp a priori em problemas deste tipo, porque é bastante flexível para acomodar diferentes opiniões iniciais sobre os parâmetros e porque é a fdp conjugada de uma verosimilhança binomial.

É importante notar que a Eq.5 é equivalente ao resultado: se $\pi \sim$ $\operatorname{Beta}(\alpha, \beta)$ e $x \mid \pi, m \sim \operatorname{Binomial}(\pi, m)$ então $\pi \mid x, m \sim \operatorname{Beta}(\alpha+x, \beta+m-x)$, um resultado básico que é utilizado diversas vezes neste trabalho.

A Moda da Posteriori é $p=(x+\alpha-1) /(m+\alpha+\beta-2)$ e é igual ao estimador MV somente se utilizamos a uniforme não informativa como fdp priori, ou seja, $\alpha=\beta=1$. Outras prioris informativas deverão influenciar na estimativa da abundância e podem ser propostas, baseando-se na distribuição dos transcritos em outras bibliotecas.

Recentemente, Morris et al. (2003) levantaram uma série de críticas contra o uso do simples estimador MV, $p=x / m$, na análise de SAGE. Apesar do comum uso do modelo Binomial, estes autores enfatizam que os dados de SAGE provêm, em verdade, de uma amostragem Multinomial incompleta:

$$
L(\mathbf{x} \mid \pi, m)=m ! \prod_{j=1}^{t} \frac{\pi_{j}^{x_{j}}}{x_{j} !}
$$

onde $\pi_{j}$ é a abundância e $x_{j}$ as contagens da $j$-ésima $\operatorname{tag}, \pi \in\left\{\left(\pi_{1}, \ldots, \pi_{t}\right): \pi\right.$. $>0, \Sigma \pi .=1\}, t$ é o número de tags únicas e $m$ é o total de tags seqüenciadas.

Por "incompleta" queremos dizer que $t$ é desconhecido, mas para prosseguir com o modelamento destes autores é preciso assumir que é conhecido anteriormente. Neste modelo $\pi_{j}=0$ não é permitido, mas para uma tag sabidamente existente e não observada o estimador MV é $p=0$. 
Uma vez que (assumimos que) sabemos o número de tags transcritas, $x_{j}$ $=0$ significa $\pi_{j}<1 / \mathrm{m}$. Essas tags são chamadas por eles de subrepresentadas (underrepresented) e, uma vez que $\Sigma \pi .=1$ por construção, as outras tags estão sobre-representadas (overrepresented). Os autores sugerem que este não é um efeito desprezível devido ao grande desequilíbrio da distribuição dos transcritos na direção dos transcritos de baixa expressão, e propõe um estimador shrinkage não-linear ("Robin Hood") para a abundância. É muito importante notar que a hipótese de conhecer quais são todos os transcritos expressos numa dada condição, ou seja, conhecer $t$, é muito forte na prática. Stern et al. (2003) apontaram a incapacidade dos estudos usuais de SAGE em estimar $t$, argumentando que os $m$ utilizados deveriam ser bastante maiores do que os que são utilizados em geral. Essa hipótese é a maior limitação do estimador Bayesiano de Morris et al. (2003).

\subsection{Estimação por Intervalo}

Uma segunda e complementar abordagem para obter informação quantitativa acerca dos parâmetros desconhecidos é por meio da Estimação por Intervalo, ou em termos informais, definir barras-de-erro para as quantidades.

O processo de SAGE é análogo ao bem conhecido problema de "bolas e urnas". Na prática isso significa que a teoria necessária para tratar o problema já está amplamente conhecida, com os modelos estatísticos bem embasados fisicamente. Dada a natureza de "contagem" dos dados de SAGE, é muito simples exprimir os resultados de abundância com algum tipo de barra-de-erro.

Usando estatística Bayesiana básica, como no Capítulo 3.1, e escolhendo uma fdp a priori não-informativa uniforme, a Eq.5 mostra que a abundância de uma tag é $\pi \mid x, m \sim \operatorname{Beta}(1+x, 1+m-x)$, onde $x$ são as contagens e $m$ o total de tags seqüenciadas na biblioteca. Uma vez definido um nível desejado de credibilidade $\alpha$, é preciso apenas integrar em torno do pico da fdp posteriori até que essa probabilidade seja atingida (Fig. 5). 

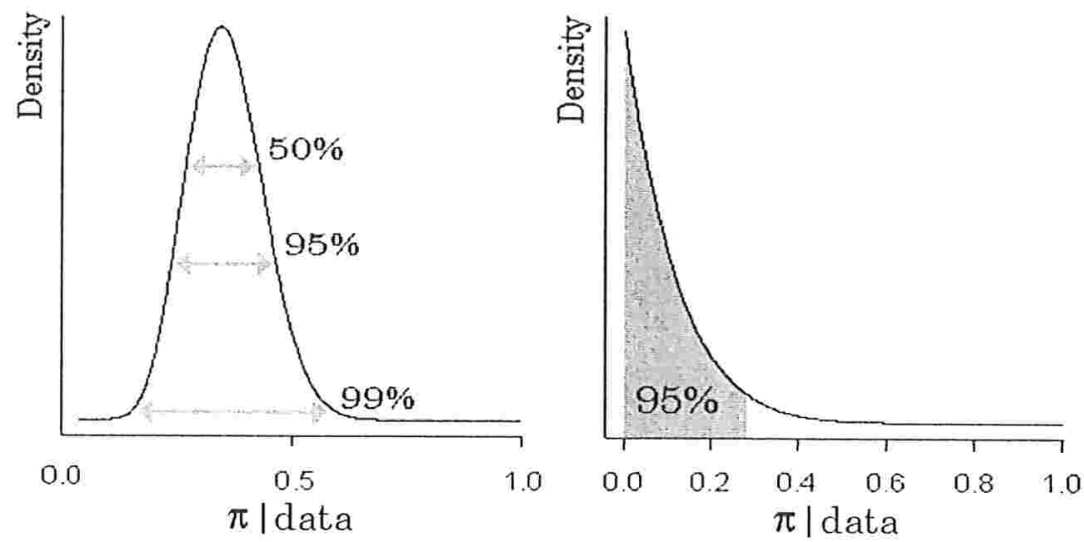

Fig. 5 - Construção das barras-de-erro. Esquerda: 3 exemplos de intervalos de credibilidade. Direita: o pico da posteriori pode coincidir com os extremos.

Uma tag com $x=16$ contagens em $m=80,000$ tem uma abundância de $2.0 \cdot 10^{-4}$ e seus intervalos de $68 \%$ e $95 \%$ de credibilidade são [1.5.10. $\left.{ }^{4} ; 2.5 \cdot 10^{-4}\right]$ e $\left[1.2 \cdot 10^{-4} ; 3.1 \cdot 10^{-4}\right]$, respectivamente. Uma tag com $x=32$ e $m$ $=160,000$ tem também uma abundância de $2.0 \cdot 10^{-4}$, entretanto, seus intervalos de $68 \%$ e $95 \%$ de credibilidade são mais precisos, respectivamente $\left[1.7 \cdot 10^{-4} ; 2.4 \cdot 10^{-4}\right]$ e $\left[1.4 \cdot 10^{-4} ; 2.7 \cdot 10^{-4}\right]$, como seria esperado intuitivamente.

Em algumas situações, os pesquisadores preferem modelar esse tipo de eventos raros, como é o caso em SAGE, utilizando variáveis aleatórias com distribuição Poisson. Nesse caso o parâmetro de interesse não é mais a abundância mas $\operatorname{sim} \lambda$, o número de contagens em $m$ (notar que $\lambda=m \pi$ ).

Audic \& Claverie (1997) relembram a solução Freqüentista para este problema, a fórmula de Ricker, para achar intervalos de $\alpha \%$ de confiança $\left[\lambda_{1} ; \lambda_{2}\right]$ para $\lambda$ :

$$
\begin{aligned}
& \lambda_{1}=\arg _{\lambda}\left(\min _{\mathfrak{R}_{+}}\left(\mid \frac{1-\alpha}{2}-1+\sum_{k=0}^{x-1}\left[\frac{e^{-\lambda} \lambda^{k}}{k !}\right]\right)\right) \\
& \lambda_{2}=\arg _{\lambda}\left(\min _{\Re_{+}}\left(\mid \frac{1-\alpha}{2}-\sum_{k=0}^{x}\left[\frac{e^{-\lambda} \lambda^{k}}{k !}\right]\right)\right)
\end{aligned}
$$

Usando essa abordagem diferente para os mesmo números que anteriormente $x=16$ e $m=80,000$ obtém-se $\lambda=16.0 \mathrm{com}[12.0 ; 21.1] \mathrm{e}$ 
[9.1;26.0] para os intervalos de $68 \%$ e $95 \%$ de confiança respectivamente, ou usando a abundância como resultado $\lambda / \mathrm{m}=2.0 \cdot 10^{-4}$ com $\left[1.5 \cdot 10^{-4} ; 2.6 \cdot 10^{-4}\right]$ e $\left[1.1 \cdot 10^{-4} ; 3.2 \cdot 10^{-4}\right]$, respectivamente. Neste exemplo os resultados obtidos com as métodos Bayesiano e Freqüentista foram muito similares, mas isso não é um resultado geral. Existem vários exemplos na literatura estatística onde a utilização destas duas abordagens leva à resultados distintos.

$\mathrm{Na}$ análise de expressão gênica, técnicas baseadas em hibridização, como as técnicas de microarray ou o tradicional northern blot resultam, por construção, em resultados relativos, isto é, razões de expressão. Dadas as abundâncias de dois genes obtidas por SAGE, é fácil transformá-las numa razão de expressão, mas o caminho contrário é impossível.

Atualmente, a única solução conhecida para Estimação por Intervalo da razão de expressão em SAGE é a solução Bayesiana apresentada por nós recentemente (Vêncio et al., 2003), chamado método SAGEci. A proposição de tal método é resultado deste Projeto de Mestrado.

Como visto anteriormente, $\pi \mid x, m \sim \operatorname{Beta}(x+1, m-x+1)$, mas para duas classes A e B a fdp da razão de expressão $R=\left(\pi_{\mathrm{A}} \mid x_{\mathrm{A}}, m_{\mathrm{A}}\right) /\left(\pi_{\mathrm{B}} \mid x_{\mathrm{B}}, m_{\mathrm{B}}\right)$ é desconhecida analiticamente.

Nossa solução consiste em simular números pseudo-aleatórios segundo as Betas de cada classe e tomar, par-a-par, um valor para $R^{(k)}$ para cada $k$-ésima simulação. Quando o número de simulações é relativamente grande, o conjunto de todos os valores de $R^{(k)}$ obtidos permitem estimar empiricamente a fdp de $R$. Na realidade não é a variável $R$ que é obtida, mas sim uma reparametrização dela $Q=$ $1 /(1+R) \in[0 ; 1]$ pois é bem mais adequada a ser submetida ao estimador não-parametrico de distribuição Kernel Density Estimators (Venables \& Ripley, 1999) pois $R \in[0 ; \infty]$. Entretanto, uma vez obtidos os intervalos de credibilidade desejados sobre a fdp estimada de $Q$, é fácil retornar a parametrização usual em $R$ resolvendo os extremos de $Q$ para $R$.

A Fig. 6 mostra um exemplo da mecânica do procedimento computacional. 
a)

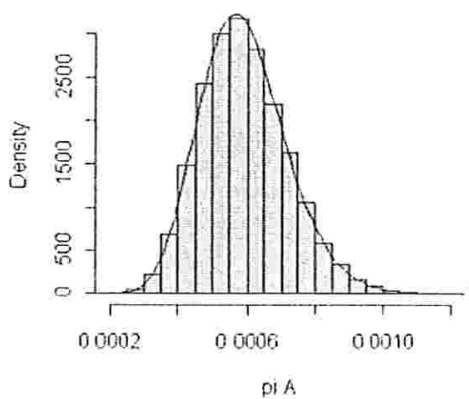

b)

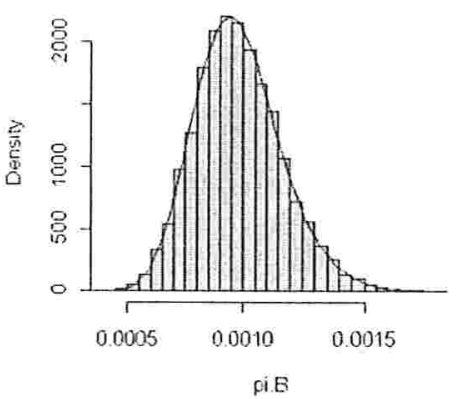

c)

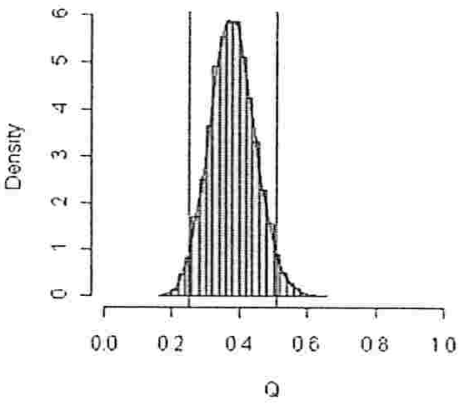

Fig. 6 - Exemplo de obtenção de barras-de-erro para razão de expressāo. Em a) e b) estão os histogramas e a curva teórica das fdp Beta que descrevem cada cada classe. Foram geradas 20000 observações. Em c) está o histograma resultado da combinação das observações simuladas e a curva é a estimativa por Kernel da fdp. As linhas verticais delimitam o intervalo de $95 \%$ de credibilidade. Obtido de Vêncio et al. (2003).

O resultado final para uma dada tag poderia ser apresentado como, por exemplo, $R=5,8$ com os possíveis cenários para os intervalos de $95 \%$ de credibilidade: $[5,5 ; 6,0],[1,2 ; 15,3],[2,2 ; \infty]$ ou $[0,3 ; 25,5]$, ao invés do simples e ainda usual 5,8-fold. O primeiro cenário é a situação ideal, com um intervalo intuitivamente pequeno, indicando um resultado preciso na razão de expressão. O segundo cenário sugere que, apesar da tag estar diferencialmente expressa, o aspecto quantitativo é pobre pois as possibilidades de razão são muito grandes já que o intervalo é largo. O terceiro cenário mostra que a única conclusão segura é que a razão de expressão é maior que 2,2 vezes. Finalmente o quarto e último cenário mostra que, não é possível saber com segurança sequer se a tag é mesmo diferencialmente expressa uma vez que o intervalo cruza a barreira de $R=1$ (classe A é igual a classe B), apesar de obtida uma razão de expressão de 5,8 vezes que intuitivamente pareceria significativa numa análise superficial.

A apresentação dos resultados pela comunidade SAGE com barrasde-erro, isto é, a aplicação da Estimação por Intervalo, ainda não é uma prática comum, mas a facilidade de execução desta deveria torná-la bem difundida entre os Biólogos. Neste trabalho, propomos que tal cuidado na apresentação dos resultados deveria ser tomado sempre. 


\section{Capítulo 4}

\section{Detecção de Expressão Diferencial}

Apesar do SAGE ser uma técnica inovadora do ponto de vista biológico, é, do ponto de vista estatístico, um velho e bem conhecido problema: retirar bolas coloridas de urnas.

No que segue iremos discutir a comparação entre bibliotecas e suas possibilidades, mas é preciso ter sempre em mente que SAGE é um tipo de dado biológico de difícil obtenção. Isso significa que muitas vezes não estão disponíveis suficientes amostras para serem comparadas por exemplo por que a doença em questão pode ser rara, ou porque obter o material biológico pode ser uma questão técnica difícil. Para esses casos, em que não há replicação biológica dos experimentos, existem vários métodos para comparação aos pares de bibliotecas únicas. Do ponto de vista estatístico essas comparações podem parecer inapropriadas, como se, por exemplo, estivéssemos medido o peso de uma única pessoa com uma balança de precisão e querendo fazer afirmações sobre como se comporta o peso das pessoas em geral (evidentemente a variância da balança deve ser menor que o da população de pessoas). Como o SAGE, o "Digital Northern" ou MPSS não são técnicas baratas e simples, queremos salientar que nessa área é muito importante que os dados gerados sejam disponibilizados em bancos-de-dados públicos, para que as análises sejam mais gerais e não exemplos complexos do mesmo equívoco exemplificado acima.

Somente recentemente a comunidade SAGE aprendeu a lidar com a variabilidade intra-classes, ou também denominada entre-bibliotecas, em suas análises (Baggerly et al., 2003). Até então, os métodos de detecção de genes diferencialmente expressos agregavam todas as observações de contagens das bibliotecas pertencentes a uma mesma classe em "pseudo-bibliotecas" para poder utilizar as técnicas já disponíveis de comparação por pares.

Num típico problema de comparação entre classes de câncer, por exemplo, os pesquisadores eram levados a somar todas as contagens das bibliotecas normais e comparar com a soma de todas as bibliotecas de câncer, ignorando a informação sobre a variabilidade biológica entre os indivíduos dos quais as bibliotecas que compõem cada classe foram feitas. 


\subsection{Bibliotecas Únicas ou "Pseudo-bibliotecas"}

Existem muitos métodos para trabalhar com bibliotecas únicas em cada classe, isto é, métodos que consideram somente a variabilidade devido ao erro de amostragem do seqüenciamento. Mesmo quando réplicas biológicas estão disponíveis, é muito comum nos estudos de SAGE construir "pseudo-bibliotecas" agregando as contagens das réplicas biológicas e usar métodos de bibliotecas únicas.

Existem 3 grupos claros de métodos para análise de bibliotecas únicas: baseados em simulação, Freqüentistas e Bayesianos.

$\mathrm{O}$ método baseado em simulação mais bem conhecido é o que foi usado no trabalho original publicado na revista Science (Zhang \& Zhou et al., 1997) descrevendo o uso do SAGE para analise de genes diferencialmente expressos. Alguns detalhes do algoritmo desses autores só estão disponíveis dentro do código-fonte proprietário do software de simulação (Prof. Kinzler - Johns Hopkins University School of Medicine, comunicação pessoal). Somente com que é descrito no trabalho original é impossível reproduzir este método, que é um dos mais utilizados na área pois faz parte do software oficial da Genzyme Corp., empresa detentora da patente do processo SAGE e que licencia para todos os usuários do mundo.

Para encontrar tags diferencialmente expressas entre duas bibliotecas A e B, são gerados conjuntos de dados simulados por uma estratégia Monte Carlo. Cria-se cada um dos $k$ dados simulados distribuindo as $\left(x_{j A}+x_{j B}\right)$ contagens da $j$-ésima tag de acordo com a seguinte regra, repetindo-a para todas as $t$ tags únicas:

$\left\{\begin{array}{l}x_{j A}^{(k)}=\sum_{z=1}^{x_{j A}+x_{j B}} 1_{\left\{u_{z} \leq m_{A}\left(m_{A}+m_{B}\right)^{-1}\right\}} \quad u \sim U_{[0 ; 1]} \\ x_{j B}^{(k)}=x_{j A}+x_{j B}-x_{j A}^{(k)}\end{array}\right.$

onde $u_{z}$ são realizações de uma fdp uniforme, $1_{1}$ é a função indicadora e $m$ é o total de tags seqüenciadas em cada biblioteca.

Para quantificar a evidência de interesse em uma tag eles definiram uma medida chamada $P$-chance $K$ :

$$
K_{j}=\frac{\min \left(100, \sum_{k=1}^{100000} 1_{\left\{\left|x_{j A}^{(k)}-x_{j B}^{(k)}\right| \geq\left|x_{j A}-x_{j B}\right|\right\}} 1_{\left\{\left(x_{j A}^{(k)}-x_{j B}^{(k)}\right) \cdot\left(x_{j A}-x_{j B}\right) \geq 0\right\}}\right)}{\min (\text { tot }, 100000)}
$$

onde tot é: 
$\sum_{k=1}^{\text {tot }} 1_{\left\{\left|x_{j A}^{(k)}-x_{j B}^{(k)}\right| \geq\left|x_{j A}-x_{j B}\right|\right\}} 1_{\left\{\left(x_{j A}^{(k)}-x_{j B}^{(k)}\right) \cdot\left(x_{j A}-x_{j B}\right) \geq 0\right\}}=100$

Essa é só uma maneira formal de dizer que o software desses autores simula amostras até que 100 ocorrências do evento "a diferença nos dados simulados é igual/maior que a verdadeira diferença observada" ou até que um limite de 10000 simulações sejam feitas, contando-se as ocorrências até este limite.

A seleção de um $K$ significativo é feita comparando-se o obtido com outros obtidos utilizando dados artificiais que representam uma proposta para a hipótese nula de não existência de expressão diferencial entre as bibliotecas:

$x_{j A N}=x_{j B N}=\frac{x_{j A}+x_{j B}}{2}$

Repetindo o mesmo processo de Eq.8 e Eq.9 para esse conjunto de dados "nulo" é possível escolher um $K$ adequado para as diferenças obtidas experimentalmente.

Os softwares SAGE300 e SAGE2002 (Genzyme Corp.) implementam esse método utilizando 40 conjuntos "nulos" para qualificar $K$ e também os parâmetros numéricos 100 e 10000 da Eq.9. Conhecendo o algoritmo completo, agora é possível implementá-lo em outras linguagens e modificar esses parâmetros numéricos à vontade.

A abordagem Freqüentista é baseada na proposição de uma função dos dados (uma estatística) e a determinação da fdp desta função quando não deveriam haver diferenças entre as duas classes testadas, isto é, a chamada distribuição nula. Deste panorama conceitual vem o sentido do P-valor, poder do teste, tamanho do teste, etc. Está sempre baseada no fato de que existe alguma (assumida?) distribuição da qual os dados são gerados e o pesquisador tenta estimar suas conclusões equivocadas (falsos positivos e falsos negativos) frente a essa fdp subjacente.

Existem muitos trabalhos na literatura Estatística comparando métodos para testar proporções. Comparações, no contexto de SAGE, também já foram publicadas (Man et al., 2000; Romualdi et al., 2001; Ruijter et al., 2002). Alguns estudos mostram pequenas vantagens de um método sobre outros, porém Ruijter et al. (2002) lembram que essas diferenças são técnicas e desprezíveis frente a aproximação drástica de não se utilizar réplicas biológicas, isto é, de se usar o paradigma de "uma medida". Iremos discutir métodos que utilizam as replicas biológicas no Capítulo 4.2. 
Os principais métodos Freqüentistas utilizados em SAGE são os clássicos Teste Exato de Fisher para tabelas de contingência e as aproximações baseadas no teste $\mathrm{Z}$ ou no teste $\chi^{2}$, que por sua vez usam resultados assintóticos para obter seus $P$-valores.

Para algum nível de significância $\alpha$ definido arbitrariamente, o teste de Fisher rejeita $\mathrm{H}_{0}$, isto é, afirma que existe expressão diferencial se:

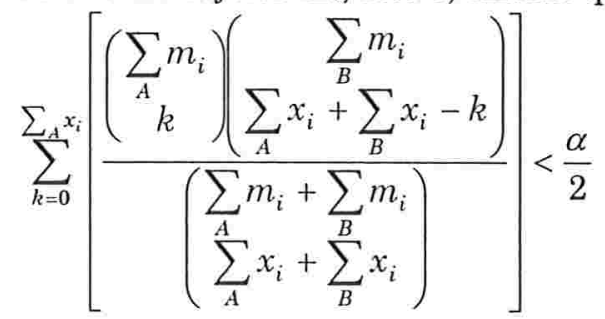

onde $m_{i}$ é o total de tags seqüenciadas na $i$-ésima biblioteca, $x_{i}$ é o número de contagens de uma dada tag na $i$-ésima biblioteca, e ambas estão somadas sobre todas as bibliotecas das classes A e B.

Para valores grandes de $m$, o cálculo dos termos combinatórios tornase dificil, mas as aproximações usuais torna-se bastante precisas.

O teste aproximado mais conhecido na comunidade SAGE é o sugerido por Kal et al. (1999). Para um dado nível de significância $\alpha$, eles dizem que existe expressão diferencial se:

$\left|\frac{\frac{\sum_{A} x_{i}}{\sum_{A} m_{i}}-\frac{\sum_{B} x_{i}}{\sum_{B} m_{i}}}{\sqrt{\left(\frac{\sum_{A} x_{i}+\sum_{B} x_{i}}{\sum_{A} m_{i}+\sum_{B} m_{i}}\right)\left(1-\frac{\sum_{A} x_{i}+\sum_{B} x_{i}}{\sum_{A} m_{i}+\sum_{B} m_{i}}\right)\left(\frac{1}{\sum_{A} m_{i}}+\frac{1}{\sum_{B} m_{i}}\right)}}\right|>Z_{\frac{\alpha}{2}}$

onde $m_{i}$ é o total de tags seqüenciadas na $i$-ésima biblioteca, $x_{i}$ é o número de contagens de uma dada tag na $i$-ésima biblioteca e o valor de $\mathrm{Z}_{\alpha / 2}$ é obtido da Normal padrão:

$\int_{-\infty}^{Z_{a / 2}} \frac{1}{\sqrt{2 \pi}} e^{-\frac{\eta^{2}}{2}} d \eta=\frac{\alpha}{2}$

As abordagens Bayesianas seguem a Teoria Estatística Bayesiana, usando a regra de Bayes para ir da informação prévia, a chamada fdp $a$ priori, para a informação atualizada pelas observações experimentais, a chamada fdp a posteriori. Elas trabalham no espaço paramétrico e não consideram a existência de "dados que poderiam ser observados mas 
não o foram", isto é, o espaço amostral. Portanto, o $P$-valor Bayesiano não tem a mesma interpretação do Freqüentista, evitando questões como correção de Bonferroni, resultados assintóticos, etc.

É fácil rescrever a Eq.5 para acomodar várias amostras separadas de um processo de Bernouli, somente generalizando a função de verossimilhança:

$\Lambda(\mathbf{X} \mid \pi)=\prod_{i=1}^{n} L\left(x_{i} \mid \pi\right) \propto(1-\pi)^{\sum_{i=1}^{n} m_{i}-\sum_{i=1}^{n} x_{i}} \pi \sum_{i=1}^{n} x_{i}$

Isso significa que $\pi \mid$ dados $\sim \operatorname{Beta}\left(\alpha+\sum x\right.$., $\beta+\sum m .-\sum x$. $)$ para ambas as classes A e B. Existem vários métodos para ordenar a hipótese de "igualdade das abundâncias das classes", indo desde o simples Bayes Error Rate (Taxa de Erro de Bayes) (Duda et al., 2000); passando pelo famoso Teste de Jeffreys (Jeffreys, 1961) para a hipótese precisa; até o teste genuinamente Bayesiano FBST - Full Bayesian Significance Test introduzido recentemente (Pereira \& Stern, 1999; Madruga et al., 2003).

A análise da igualdade das abundâncias $\pi_{\mathrm{A}}=\pi_{\mathrm{B}}$ não é o único paradigma que pode ser usado. É possível analisar existência de expressão diferencial diretamente sobre as contagens absolutas $\Sigma x$. ou usando a razão de expressão $\pi_{\mathrm{A}} / \pi_{\mathrm{B}}$.

Os métodos Bayesianos mais conhecidos na comunidade SAGE que utilizam esses paradigmas alternativos são os métodos de Audic \& Claverie (1997) e o método implementado no SAGEmap e SAGE Genie (Lal \& Lash et al., 1999).

O método de Audic \& Claverie foi criado para o contexto de contagens de ESTs ("Digital Northern") e não é um método complemente Bayesiano uma vez que a passagem da priori para a posteriori é apenas um passo intermediário em direção à solução final. Supondo que a distribuição Poisson é uma boa aproximação para o processo de amostragem em SAGE, esses autores escreveram a probabilidade de observar os resultados da primeira classe dado os resultados da segunda classe. Existe expressão diferencial, com uma probabilidade $\alpha$ definida previamente, se:

$\sum_{k=\Sigma_{B} x_{i}}^{\infty}\left[\frac{\left(k+\sum_{A} x_{i}\right) !}{\left(\sum_{A} x_{i}\right) ! k !}\left(\frac{\sum_{B} m_{i}}{\sum_{A} m_{i}}\right)^{k}\left(1+\frac{\sum_{B} m_{i}}{\sum_{A} m_{i}}\right)^{-k-\sum_{A} x_{i}-1}\right]<\frac{\alpha}{2}$

onde $m_{i}$ é o total de tags seqüenciadas na $i$-ésima biblioteca e $x_{i}$ é 0 número de contagens de uma dada tag na $i$-ésima biblioteca. 
Outro método Bayesiano bem conhecido na comunidade SAGE é o método adaptado por Lal \& Lash et al. (1999) de Chen et al. (1998) para acomodar bibliotecas, ou "pseudo-bibliotecas", com diferentes totais seqüenciados. Este método é o que está implementado nos importantes banco-de-dados públicos: National Center for Biotechnology Information's SAGEmap (http://www.ncbi.nlm.nih.gov/SAGE) e National Cancer Institute's Cancer Genome Anatomy Project - SAGE Genie (http://cgap.nci.nih.gov/SAGE). Esses bancos-de-dados determinam a probabilidade posterior de desequilíbrio (fold-changes) na razão de expressão entre as duas classes maiores que um certo valor arbitrário $R$. É importante notar que este teste responde uma pergunta acerca de uma dada razão de expressão e é responsabilidade de cada pesquisador definir o quanto este acredita ser uma razão de expressão indicativa de expressão diferencial. $O$ teste então associa uma probabilidade a afirmações acerca deste limite arbitrariamente definido. Fixada uma probabilidade $\alpha$ aceitável e um valor de corte $R$, existe expressão diferencial se:

$$
\frac{\int_{R}^{1} q_{A}^{c+\sum_{A} x_{i}}(1-q)^{c+\sum_{B} x_{i}}\left(1+\frac{\sum_{A} m_{i}}{\sum_{B} m_{i}} q-q\right)^{-\left(\sum_{A} x_{i}+\sum_{B} x_{i}\right)} d q}{\int_{0}^{1} q^{c+\sum_{A} x_{i}}(1-q)^{c+\sum_{B} x_{i}}\left(1+\frac{\sum_{A} m_{i}}{\sum_{B} m_{i}} q-q\right)^{-\left(\sum_{A} x_{i}+\sum_{B} x_{i}\right)} d q}>\alpha
$$

onde $m_{i}$ é o total de tags seqüenciadas na $i$-ésima biblioteca, $x_{i}$ é o número de contagens de uma dada tag na $i$-ésima biblioteca e $c$ é uma constante que vem da fdp a priori. Nas ferramentas do SAGEmap e do SAGE Genie, por exemplo, assume-se $c=3$ (Lal \& Lash et al., 1999).

A Eq.16 é valida para razões de expressão $R$ em que se escreve a classe A em relação a classe $\mathrm{B}$ e quando $R \geq 1$, isto é, $p_{\mathrm{A}} \geq p_{\mathrm{B}}$. Quando isso não acontecer, ou seja, quando $R \leq 1$, basta apenas permutar os nomes das classes $\mathrm{A}$ e B na equação e utilizar a mesma fórmula, por simplicidade.

A Fig. 7 mostra um exemplo da mecânica de cálculo para $\Sigma_{\mathrm{A}} m=$ $80.000, \Sigma_{\mathrm{A}} x=60, \Sigma_{\mathrm{B}} m=50.000, \Sigma_{\mathrm{B}} x=10, p_{\mathrm{A}} / p_{\mathrm{B}}=3,75$ vezes de expressão. 


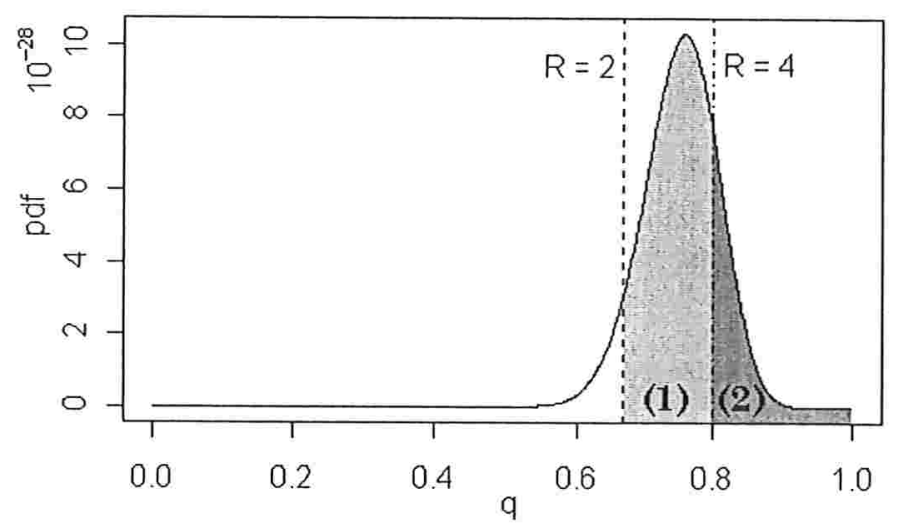

Fig. 7 - Ilustração do método do SAGEmap e SAGE Genie (Lal \& Lash et al., 1999). $R$ são as razões de expressão gênica, (2) e (1)+(2) são as probabilidades posteriores de mudanças de 4 -vezes e 2-vezes, respectivamente, para o exemplo numérico do texto.

Usando o método implementado no SAGEmap e SAGE Genie, obtemos pela Eq.16: $\mathbf{P}(R \geq 2)=\mathbf{P}(0,666 \leq q \leq 1)=0,93$, representado pelas áreas sombreadas (1)+(2) na Fig. 7. Outro exemplo é $\mathbf{P}(R \geq 4)=$ $\mathrm{P}(0,8 \leq q \leq 1)=0,19$, a área sombreada (2) na figura. Portanto existe pouca chance que a razão de expressão seja maior que 4 vezes, mas considerável chance que seja mais que 2 vezes mais expressa na classe A que na classe B.

\subsection{Bibliotecas com Réplicas Biológicas}

Suponha que alguém está amostrando bolas coloridas de várias urnas. Além disso, antes de escolher uma urna de onde sorteia-se uma bola, é preciso escolher ao acaso qual urna será amostrada. Para tirar conclusões genéricas sobre as bolas azuis, por exemplo, é preciso pesar a amostragem pela probabilidade de se escolher uma urna particular, especialmente se soubermos que as urnas têm abundâncias diferentes de bolas azuis.

Uma situação muito semelhante acontece quando estamos lidando com réplicas biológicas das bibliotecas na análise SAGE. Assim como nas diferentes urnas da ilustração acima, é fácil aceitar o fato intuitivo de que as diferentes réplicas de bibliotecas de uma classe, feitas a partir 
de indivíduos diferentes, devam ter abundâncias diferentes para uma tag qualquer.

Para uma dada tag, o processo de contagem na $i$-ésima biblioteca é usualmente modelado por um processo de Bernoulli com uma abundância fixada e desconhecida $\pi_{i} \in[0 ; 1]$. A fdp da abundância entre as $n$ bibliotecas é desconhecida e $\pi_{i}$ é considerada como a $i$-ésima realização da variável aleatória $\pi \in[0 ; 1]$. A verossimilhança de um resultado particular de contagens $x_{i}$ no total $m_{i}$ de tags seqüenciadas é freqüentemente modelada por uma fdp Binomial. O processo de pesar tal Binomial pela abundância leva naturalmente ao modelo de misturas (Bueno et al., 2002):

$L\left(x_{i} \mid m_{i}, \theta\right)=\int_{0}^{1} f(\pi \mid \theta)\left(\begin{array}{c}m_{i} \\ x_{i}\end{array}\right)(1-\pi)^{m_{i}-x_{i}} \pi^{x_{i}} d \pi$

A função $f(\cdot)$ é a fdp desconhecida da abundância $\pi$ da tag, sendo tudo que precisamos/queremos saber. Esta função é parametrizada em $\theta$.

Este é um modelo de mistura, com a Binomial sendo a distribuição de mistura. Entretanto, outras escolhas podem ser feitas, como por exemplo uma distribuição de Poisson (Bueno et al., 2002).

Num experimento de SAGE não se sabe, antes de se realizar os experimentos, quantas tags poderão ser geradas ao total. Isso quer dizer que a regra de parada da amostragem é desconhecida e portanto $m$ é também uma variável aleatória. Portanto, se formos matematicamente bastante rigorosos, a distribuição de probabilidade associada às contagens não pode ser uma Binomial pois nesta $m$ é dado. Entretanto, a diferença entre esta formulação e a mais rigorosa possível deveria ser apenas uma constante multiplicativa na função de Verossimilhança, que seria cancelada mais tarde na construção de qualquer fdp posteriori, e portanto não implica numa discrepância importante do ponto de vista prático. É interessante notar que, em geral, essa pode ser uma fonte de discrepância entre resultados obtidos por métodos Freqüentistas e Bayesianos.

Num trabalho submetido à publicação recentemente (Vêncio et al., 2004), nós mostramos que o modelo Binomial, utilizado atualmente por quase todos os métodos de análise estatística em SAGE, pode ser obtido como um caso particular do modelo de mistura se tomarmos $f(\cdot)$ como 
uma fdp degenerada sobre algum valor $\theta$, i.e., uma função Delta de Dirac restrita à $[0 ; 1]$ :

$$
\begin{aligned}
L\left(x_{i} \mid m_{i}, \theta\right) & =\int_{-\infty}^{\infty} \mathbf{1}_{\{0 \leq \pi \leq 1\}} \delta(\pi-\theta)\left(\begin{array}{c}
m_{i} \\
x_{i}
\end{array}\right)(1-\pi)^{m_{i}-x_{i}} \pi^{x_{i}} d \pi \\
& =\left(\begin{array}{c}
m_{i} \\
x_{i}
\end{array}\right)(1-\theta)^{m_{i}-x_{i}} \theta^{x_{i}}
\end{aligned}
$$

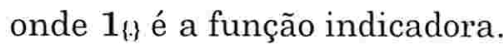

Assumindo tal função, estamos tacitamente ignorando a possibilidade de variabilidade entre as bibliotecas devido a qualquer outra razão que não a devida à amostragem uma vez que somente $\pi=\theta$ tem densidade de probabilidade positiva.

A simplicidade do resultado apresentado acima encerra uma afirmação de grande peso conceitual, sendo talvez um dos resultados mais importantes obtidos neste Projeto de Mestrado.

Colocada desta forma, fica explicito o equívoco envolvido em todos os métodos que utilizam "pseudo-bibliotecas". Mesmo quando réplicas biológicas estão disponíveis, é comum a adoção desta aproximação grosseira na análise de SAGE.

Utilizando um modelo bastante mais realista para $f(\cdot)$, uma alternativa é propor que a abundância de uma tag seja descrita por uma variável aleatória Beta, que tem variância não-nula:

$$
\begin{aligned}
L\left(x_{i} \mid m_{i}, \theta_{1}, \theta_{2}\right) & =\int_{0}^{d} \frac{(1-\pi)^{\theta_{2}-1} \pi^{\theta_{1}-1}}{B\left(\theta_{1}, \theta_{2}\right)}\left(\begin{array}{c}
m_{i} \\
x_{i}
\end{array}\right)(1-\pi)^{m_{i}-x_{i}} \pi^{x_{i}} d \pi \\
& =\left(\begin{array}{c}
m_{i} \\
x_{i}
\end{array}\right) \frac{B\left(\theta_{1}+x_{i}, \theta_{2}+m_{i}-x_{i}\right)}{B\left(\theta_{1}, \theta_{2}\right)}
\end{aligned}
$$

onde $B(\cdot)$ é a função especial beta.

Este é o conhecido modelo Beta-Binomial, que apareceu pela primeira vez no contexto de expressão diferencial em SAGE introduzido por Baggerly et al. (2003).

O mérito de Baggerly et al. (2003) foi, principalmente, o de perceber e alertar toda a comunidade SAGE que os métodos utilizando "pseudobilbiotecas", amplamente difundidos até então, são inadequados para comparações que dispõem de réplicas biológicas. Eles derivaram o modelo Beta-Binomial como um modelo hierárquico no contexto Freqüentista e não como um caso particular de um modelo de misturas, como proposto em Vêncio et al. (2004).

Para uma tag fixada, dados os vetores de contagens nas $n$ réplicas biológicas de uma classe $\mathrm{X}=\left(x_{1}, \ldots, x_{n}\right)$ e o vetor de totais seqüenciados 
para essas bibliotecas $\mathbf{M}=\left(m_{1}, \ldots, m_{n}\right)$, é necessário ajustar (fitting) os parâmetros modelo Beta-Binomial e testar se existe expressão diferencial.

Pela abordagem Freqüentista proposta por Baggerly et al. (2003), a equação $p_{i}=x_{i} / m_{i}$ é utilizada como o estimador de $\pi_{i}$ e uma combinação linear dessas abundâncias é proposta como o modo correto de se combinar os resultados, sendo, portanto, a quantidade de interesse. É possível mostrar que um estimador não-viciado $V_{u}$ para a variância da combinação linear é:

$$
p=\sum_{i=1}^{n} w_{i} p_{i} \quad, \quad V_{u}=\frac{\sum_{i=1}^{n} w_{i}^{2} p_{i}^{2}-\left(\sum_{i=1}^{n} w_{i}^{2}\right) p^{2}}{1-\left(\sum_{i=1}^{n} w_{i}^{2}\right)}
$$

Utilizando multiplicadores de Lagrange para encontrar os pesos $w_{i}$ da combinação linear que levam ao estimador de mínima variância, eles encontraram:

$w_{i} \propto \frac{m_{i}\left(\theta_{1}+\theta_{2}\right)}{\theta_{1}+\theta_{2}+m_{i}}$

Entretanto, este estimador de variância pode se tornar irrealisticamente pequeno quando torna-se menor que a variabilidade do processo de medida. Sabemos que a variância deste modelo não pode ser menor que a variância eventualmente obtida no modelo em que não consideramos a variabilidade intra-classe.

Como ilustração, o mesmo efeito aconteceria se estivéssemos medindo, com uma régua simples, vários diâmetros de bolas de papel amassado e diâmetros de esferas perfeitas de metal. No primeiro caso, a natureza intrínseca do objeto sendo medido dominaria a estimativa de variabilidade. Entretanto, no segundo caso, não podemos conhecer o diâmetro das esferas perfeitas com uma precisão maior do que a do nosso instrumento de medida, a régua. O mesmo acontece nessas análises de SAGE, pois se a variabilidade intrínseca biológica da tag for menor que a variabilidade introduzida pelo processo técnico de amostragem, devemos considerar este último como o mínimo possível estimável.

Essas idéias levaram Baggerly et al. (2003) a propor o estimador ad hoc:

$V=\max \left[V_{u} ; V_{\text {pseudo-lib }}\right]$

onde: 
$V_{\text {pseudo-lib }}=\frac{1}{\sum_{i=1}^{n} m_{i}} \frac{\sum_{i=1}^{n} x_{i}}{\sum_{i=1}^{n} m_{i}}\left(1-\frac{\sum_{i=1}^{n} x_{i}}{\sum_{i=1}^{n} m_{i}}\right)$

A função $\max (\cdot)$ assegura que a variância $V$ não se torne artificialmente pequena quando $V_{u}$ é menor que o limite físico razoável. É interessante notar que $V_{\text {pseudo-lib é exatamente o estimador natural }}$ para a variância se considerarmos a Eq.18 ao invés da Eq.19 como o modelo de contagem subjacente. Ainda, o termo $\Sigma x . / \Sigma m$. é equivalente à abundância se agregarmos as observações de todas as bibliotecas em "pseudo-bibliotecas".

Para ajustar todos esses parâmetros esses autores utilizam o computacionalmente prático Método dos Momentos.

Uma vez encontrados $p_{\mathrm{A}}, p_{\mathrm{B}}, V_{\mathrm{A}}$ e $V_{\mathrm{B}}$ para as classes $\mathrm{A}$ e $\mathrm{B}$, é necessário testar se as proporções são significativamente diferentes. Evocando alguns resultados assintóticos, eles propõe uma estatística $t_{w}$ que deve seguir uma fdp $t_{d f}$.

$t_{w}=\frac{p_{A}-p_{B}}{\sqrt{V_{A}+V_{B}}}$

com:

$$
t_{w} \sim t_{d f} \quad d f=\frac{\left(V_{A}+V_{B}\right)^{2}}{\frac{V_{A}^{2}}{\sum_{A} m_{i}-1}+\frac{V_{B}^{2}}{\sum_{B} m_{i}-1}}
$$

Uma abordagem diferente foi proposta recentemente por nós como resultado deste Projeto de Mestrado, também acomodando a variabilidade intra-classe, utilizando a Estatística Bayesiana e não recorrendo a aproximações assintóticas. Este método original é chamado de SAGEßBin (Vêncio et al., 2004).

Considerando a verossimilhança como na Eq.19, é fácil escrever a fdp a posteriori:

$g\left(\theta_{1}, \theta_{2} \mid \mathbf{X}, \mathbf{M}\right) \propto \mathbf{1}_{\left\{\theta_{2} \geq \sigma\right\}} \cdot \prod_{i=1}^{n} \frac{B\left(\alpha_{\theta}+x_{i}, \beta_{\theta}+m_{i}-x_{i}\right)}{B\left(\alpha_{\theta}, \beta_{\theta}\right)}$

onde a função indicadora é nossa fdp a priori. É importante notar que fizemos uma re-parametrização já que agora $\theta=\left(\theta_{1}, \theta_{2}\right)$ é a média e o desvio padrão (dp) de uma variável aleatória Beta que descreve cada classe, como suposto na Eq.19. O novo espaço paramétrico $\Theta=\left\{\left(\theta_{1}, \theta_{2}\right)\right.$ : 0 $\left.\leq \theta_{1} \leq 1,0 \leq \theta_{2}^{2}<\theta_{1}\left(1-\theta_{1}\right) \leq 1 / 4\right\}$ é mais intuitivo que o usual $(\alpha, \beta)$ e é 
limitado (muito mais adequado para procedimentos numéricos). Em Eq.26, utilizamos o sub-índice $\theta$ em $\alpha$ e $\beta$ para lembrar que são funções da nova parametrização, que por sua vez podem ser obtidos facilmente das expressões de média e dp de uma Beta.

A fdp a priori é uma uniforme sobre $\Theta$, mas restrita às variâncias maiores que as eventualmente obtidas pelo modelo usando "pseudobibliotecas". Partindo da Eq.18 e escolhendo uma uniforme como a priori, nós escrevemos a a posteriori do caso em que adota-se uma "pseudo-biblioteca" adaptando a Eq.5:

$h(\theta \mid \mathbf{X}, \mathbf{M}) \propto(1-\theta)^{\sum_{i=1}^{n} m_{i}-\sum_{i=1}^{n} x_{i}} \theta^{\sum_{i=1}^{n} x_{i}}$

Isso significa que $\theta \sim \operatorname{Beta}\left(1+\sum x\right.$., $1+\sum m .-\Sigma x$.), e portanto a variância é:

$$
\sigma=\sqrt{\frac{\left(1+\sum_{i=1}^{n} x_{i}\right)\left(1+\sum_{i=1}^{n} m_{i}-\sum_{i=1}^{n} x_{i}\right)}{\left(2+\sum_{i=1}^{n} m_{i}\right)^{2}\left(3+\sum_{i=1}^{n} m_{i}\right)}}
$$

A Teoria Bayesiana fornece uma forma natural de incorporar esse tipo de conhecimento anterior ou restrição sem precisar apelar a proposição de estimadores ad hoc como os da Eq.22, apesar da lógica e fundamentos físicos subjacentes destes serem os mesmos.

A densidade dos pontos da posteriori cuja variância está abaixo do nosso "mínimo de trabalho" é zero.

Encontra-se as duas Betas que descrevem as classes tomando a moda

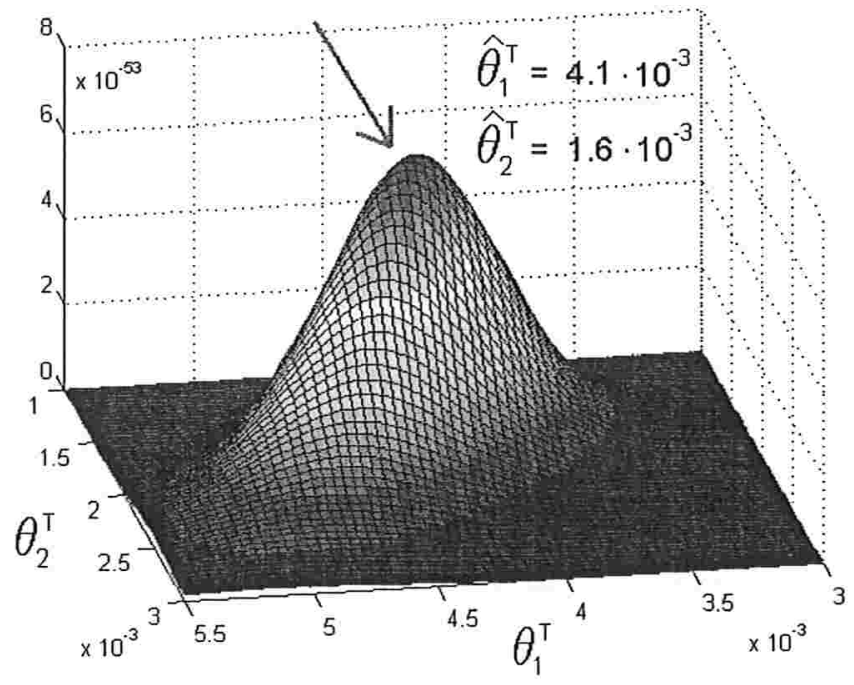

Fig. 8 - Ilustração do método utilizado para definir as fdps Beta que definem cada classe. Tomando a moda (seta) da a posteriori e utilizando-a como parâmetros da Beta (plug-in). Exemplo numérico arbitrário para a classe tumoral. Repete-se o mesmo para a classe normal. 

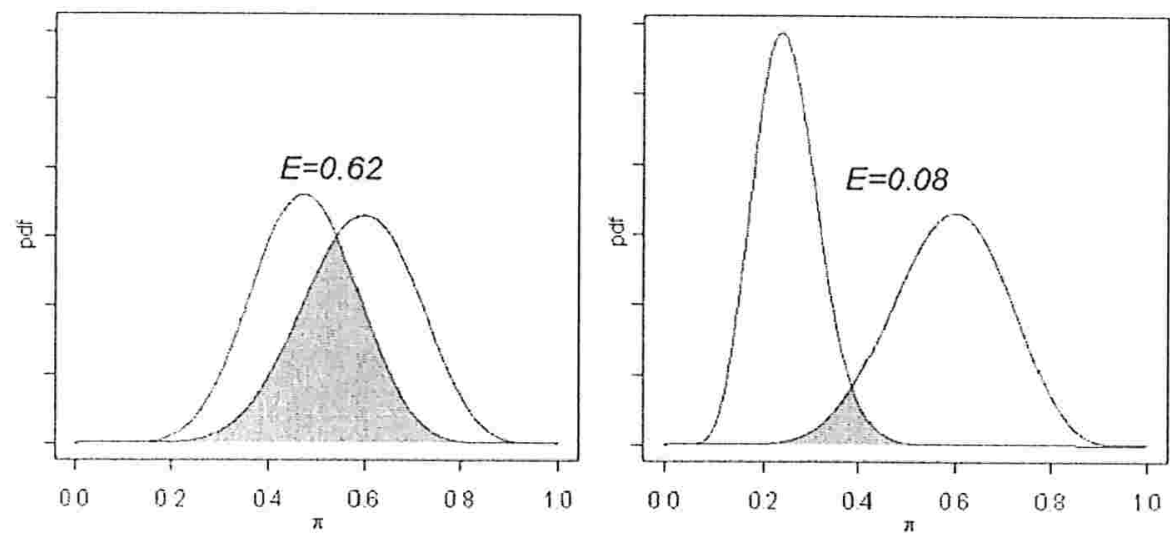

Fig. 9 - Ilustração de aplicação do Bayes Error Rate. Esquerda: não existe evidência de expressão diferencial. Direita: considerado como tendo expressão diferencial.

da fdp a posteriori, isto é, $\left(\theta_{1}, \theta_{2}\right) \in \Theta$ que levam a Eq.26 ao seu máximo. A Fig. 8 ilustra um exemplo do processo.

Finalmente, para testar se uma tag está diferencialmente expressa entre as classes, nós propomos uma medida de evidência diferente do $P$ valor. Utilizamos o intuitivo Bayes Error Rate (Taxa de Erro de Bayes):

$E=\int_{0}^{1} \min \left(f\left(\pi \mid \hat{\theta}^{A}\right), f\left(\pi \mid \hat{\theta}^{B}\right)\right) d \pi$

onde: $\hat{\theta}=\arg _{\theta}\left(\max _{\Theta}(\right.$ posteriori $\left.)\right)$

Pequenos valores de $E$ indicam que as fdps Betas estão "longe" uma das outras, indicando portanto evidência de expressão diferencial (Fig. 9). Ordena-se as tags por seus valores $E$ e permite-se que os biólogos definam eles mesmos o que entendem intuitivamente por inaceitável um certo nível de superposição entre as classes (erro de classificação).

Uma ferramenta indispensável para checar a consistência intuitiva dos resultados obtidos com qualquer método é o gráfico que representa todas as observações individuais das bibliotecas, semelhantes à Fig. 11 do Capítulo 5. Usando essa ferramenta simples, o pesquisador pode constatar facilmente a inconsistência dos métodos de "pseudo-biliotecas" em vários casos.

Para tornar nosso método facilmente acessível à comunidade SAGE, fornecendo inclusive um modo ágil de gerar os gráficos mencionados acima, nós construímos uma interface interativa pela Internet. A Fig. 
10 mostra um exemplo real de tela capturada de um processo de análise com nossa ferramenta.

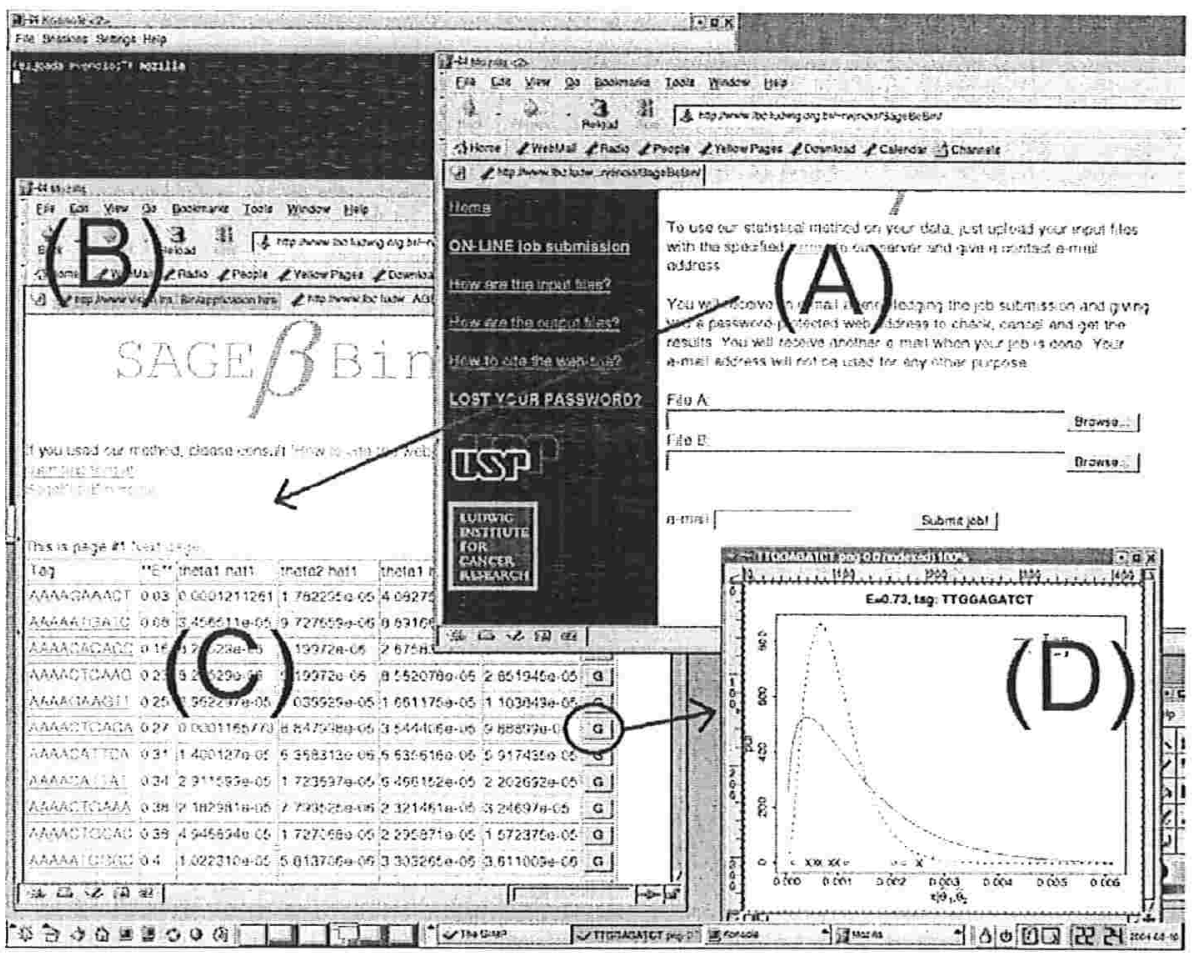

Fig. 10 - Captura de tela do método SAGEßBin desenvolvido por nós. Uma interface Web amigável facilita o uso da comunidade SAGE pois apenas é necessário alimenta-la com os dados (A), recebendo de volta uma página Web protegida por senha (B), com as tags ordenadas destacando os menores Bayes Error Rate (C). Os gráficos (D) permitem verificar intuitivamente a consistência do modelo Beta-Binomial e visualizar cada observação individualmente. Disponível em: http://www.vision.ime.usp.br/ rvencio/SAGEbetaBin.

\subsection{Múltiplas Bibliotecas}

Existe um terceiro tipo de análise/comparação que utiliza dados de contagem em Expressão Gênica que é a busca de tags discrepantes (outliers) num contexto de múltiplas bibliotecas.

Os métodos apresentados nas seções anteriores trabalham com comparações aos pares entre classes, tendo uma ou mais bibliotecas em 
cada uma e acomodando ou não as réplicas biológicas. Por outro lado, comparações entre múltiplas bibliotecas não pertencem ao paradigma de comparação aos pares, mas sim visam a busca de tags que apresentam um comportamento "não-usual" num conjunto de bibliotecas (outliers). Portanto o conceito de classe não é mais utilizado aqui, ou em outras palavras, todas as bibliotecas podem ser consideradas como classes únicas.

Provavelmente, o método mais conhecido na comunidade SAGE para detecção de outliers é o método apresentado por Stekel et al. (2000). Este método surgiu para melhorar e substituir o método introduzido por Greller \& Tobin (1999) pois este só detectava outliers muito discrepantes, sendo portanto pouco sensível.

Stekel et al. (2000) propuseram uma solução mais flexível que tenta detectar se um transcrito tem a mesma abundância em várias bibliotecas simultaneamente. Um exemplo de aplicação poderia ser tentar localizar transcritos tecido-específicos num conjunto de bibliotecas advindas de vários tecidos.

Esses autores evitaram os problemas envolvidos no emprego do $P$ valor simplesmente ordenando o valor da estatística $R$ proposta por eles. Para uma dada tag e fixado algum valor de corte $R^{*}$, afirmam que existe expressão diferencial em ao menos uma biblioteca se:

$R=\sum_{i=1}^{n}\left[x_{i} \ln \left(\frac{x_{i}}{m_{i}} \frac{\sum_{j=1}^{n} m_{j}}{\sum_{j=1}^{n} x_{j}}\right)\right]>R^{*}$

onde $x_{i}$ são as contagens para uma dada tag na $i$-ésima biblioteca, $m_{i}$ é o total de tags seqüenciadas na $i$-ésima biblioteca e $n$ é o número de bibliotecas analisadas.

Para ajudar o usuário a definir um corte $R^{*}$, esses autores propõem uma medida alternativa de evidência chamada believability. Essa medida é obtida por uma estratégia computacional usual de aleatorização das observações ou apelando para considerações assintóticas uma vez que $2 R \rightarrow \chi^{2} n$-1. 


\section{Capítulo 5}

\section{Aplicação à Dados Reais}

Para ganharmos intuição sobre o método SAGEßBin, desenvolvido pelo nosso grupo de pesquisa como resultado desse Projeto de Mestrado (Vêncio et al., 2004), fizemos uma aplicação ilustrativa deste à dados reais relevantes obtidos em bancos-de-dados públicos. A análise, bem como os programas escritos em linguagem $R$ (Ihaka \& Gentleman, 1996; http://www.r-project.org) estão disponíveis gratuitamente no website: http://www.vision. ime.usp.br/ rvencio/Mestrado.

Nosso objetivo é procurar genes diferencialmente expressos entre tumores de cérebro astrocitoma grau II e astrocitoma grau III.

As bibliotecas utilizadas são réplicas biológicas, excluídas as linhagens de células e considerando somente material de tecido fresco (bulk) extraído de diferentes pacientes. Os dados reais foram obtidos no banco-de-dados público SAGE Genie (Boon et al., 2002) no web-site: http://cgap.nci.nih.gov/SAGE. A Tabela 1 lista as bibliotecas utilizadas nessa ilustração.

Tabela 1 - Bibliotecas de tumores de Cérebro obtidas no SAGE Genie (disponíveis em janeiro de 2004)

\begin{tabular}{|l|l|r|}
\hline$\#$ & Nome da Biblioteca - Classe A & Total de tags \\
\hline 1 & SAGE_Brain_astrocytoma_grade_III_B_H1020 & 51573 \\
\hline 2 & SAGE_Brain_astrocytoma_grade_III_B_H970 & 106982 \\
\hline 3 & SAGE_Brain_astrocytoma_grade_III_B_R140 & 118733 \\
\hline 4 & SAGE_Brain_astrocytoma_grade_III_B_R927 & 107344 \\
\hline & "pseudo-biblioteca" agregando os grade III & 384632 \\
\hline$\#$ & Nome da Biblioteca - Classe B & Total de tags \\
\hline 5 & SAGE_Brain_astrocytoma_grade_II_B_H563 & 88568 \\
\hline 6 & SAGE_Brain_astrocytoma_grade_II_B_H359 & 105764 \\
\hline 7 & SAGE_Brain_astrocytoma_grade_II_B_H388 & 106285 \\
\hline 8 & SAGE_Brain_astrocytoma_grade_II_B_H530 & 102439 \\
\hline & "pseudo-biblioteca" agregando os grade II & 403056 \\
\hline
\end{tabular}

No presente trabalho não queremos focar na análise da Biologia, mas sim demonstrar, do ponto de vista matemático, as diferenças fundamentais nos métodos de análise de expressão diferencial tão enfaticamente detalhadas no Capítulo 4. Entretanto, tomamos cuidado 
em definir cada classe somente com bibliotecas advindas das mesmas condições (grau) histopatológicas e somente de tecido fresco (bulk)

Dadas as contagens de cada tag e os totais das bibliotecas, nós escolhemos utilizar para estimar a abundância de cada tag o estimador de Moda da Posteriori com uma a priori não-informativa (Eq.5) para manter a semelhança com o estimador de Máxima Verossimilhança.

Seguindo a abordagem usual nas análises de dados de SAGE e para comparação posterior com os métodos alternativos, criamos as "pseudobibliotecas", agregando as observações das tags nas bibliotecas, isto é, somando as contagens de todas as bibliotecas para uma tag fixada.

Para executar o Teste Exato de Fisher, o $\chi^{2}$, e o método de Audic \& Claverie (1997), discutidos no Capítulo 4.2; utilizamos o software gratuito IDEG6 (Romualdi et al., 2001). Este software tem uma versão on-line na Internet e calcula também os métodos de Stekel et al. (2000) e Greller \& Tobin (1999) para o contexto de multi-bibliotecas, não aplicável ao nosso exemplo. Para executar o método Bayesiano de Lash \& Lal et al. (1999), utilizamos a ferramenta on-line original do SAGE Genie.

Para executar as mesmas análises mas no contexto de bibliotecas com réplicas biológicas, como discutido no Capítulo 4.1, utilizamos as duas únicas soluções disponíveis até o memento: o método SAGEßBin (Vêncio et al., 2004) e a aproximação para teste-t de Baggerly et al. (2003).

Como anunciado enfaticamente na introdução da Capítulo 4, os resultados podem ser bastante diferentes usando a comum abordagem de "pseudo-bibliotecas" ou essas duas abordagens que levam em conta a variabilidade intrínseca intra-classe.

Uma tag considerada diferencialmente expressa, empregando os métodos que consideram a variabilidade intra-classe, sempre aparece como diferencialmente expressa empregando os métodos baseados em "pseudo-bibliotecas". Entretanto o contrário não é sempre verdadeiro.

Um exemplo claro deste efeito é obtido para a tag AATAGAAATT, que corresponde ao gene Fosfoproteina tipo I secretada (osteopontina, sialoproteína óssea tipo I, ativadora inicial de linfócitos T). Usando qualquer um dos métodos baseados em "pseudo-bibliotecas", o pesquisador é levado a acreditar que esta tag é diferencialmente expressa entre os tumores astrocitoma grau II e astrocitoma grau III com alta significância. Como calculado pelo software IDEG6, todos os métodos testados resultam $P$-valor igual a 0.00 (zero!). $O$ método implementado no SAGE Genie resulta num $P$-valor igual a 0.00 (zero) 
para uma razão de expressão maior que 2 vezes do astrocitoma grau II em relação ao astrocitoma grau III e 0.01 para uma razão de expressão maior que 4 vezes. Além disso, o método de construção de barras-deerro, SAGEci (Vêncio et al., 2003), mostra que o intervalo de $95 \%$ de credibilidade para a razão de expressão $R=5,3$ vezes é $[4,3 ; 6,7]$, muito distante do limite $R=1$ onde não há expressão diferencial.

Todos esse resultados indicam claramente para uma expressão diferencial com alta significância. Entretanto, se observarmos num gráfico simples, os resultados de abundância de todas as bibliotecas individualmente, é fácil notar que a conclusão de todos esses métodos é suspeita.

\section{$\mathrm{E}=0.48$, tag: AATAGAAATT}

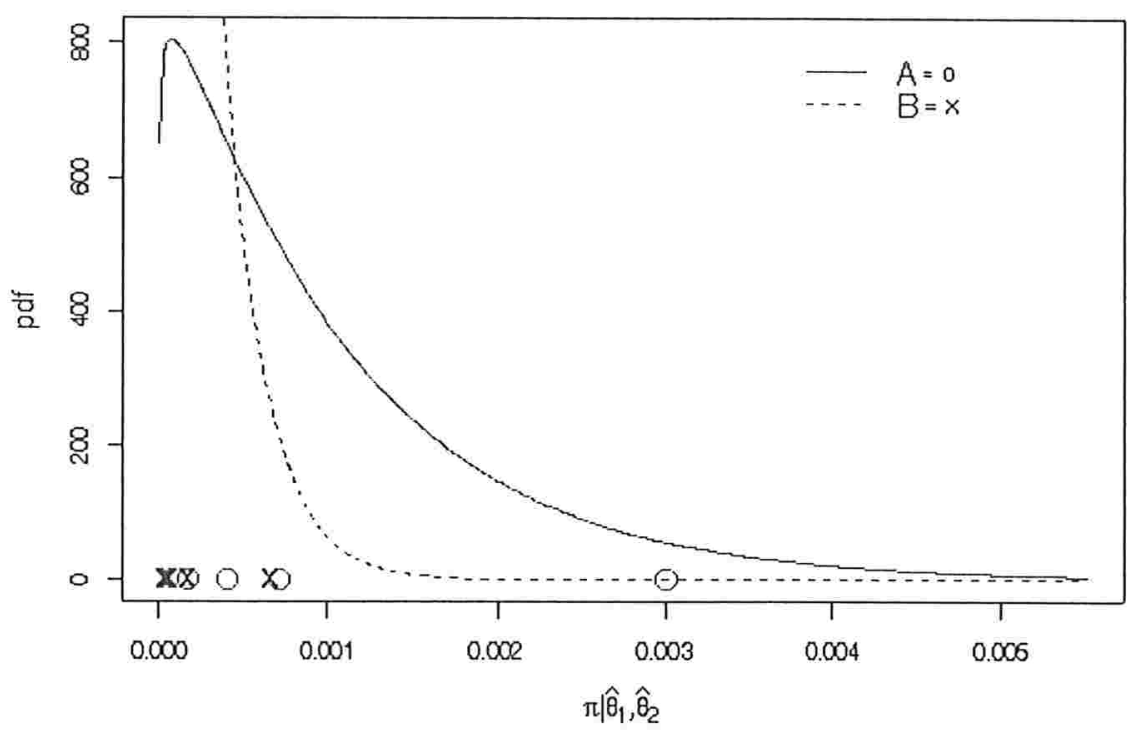

Fig. 11 - Exemplo de tag considerada diferencialmente expressa pelos métodos baseados em "pseudo-bibliotecas" mas desconsiderado pelos métodos que consideram a variabilidade intra-classe.

Por outro lado, os dois métodos que consideram a variabilidade biológica intra-classe não atribuem alta significância para esta tag, como é possível supor intuitivamente observando a superposição das cruzes (classe B, astrocitoma grau II) com os círculos (classe A, astrocitoma grau III) na Fig. 11. 
A aproximação para o teste- $t$ de Baggerly et al. (2003) resulta num $P$. valor de 0.21 , muito alto para os cortes de $\leq 0.01$ ou $\leq 0.05$, utilizados tradicionalmente. A evidência calculada pelo método SAGEßBin resulta em $E=0,48$ indicando grande superposição entre as fdps que descrevem as classes (curvas na Fig. 11), como discutido no Capítulo 4.1 (ver Fig. 9). Portanto, não há suporte estatístico para afirmar que esta tag é diferencialmente expressa, em termos gerais.

Esse é um exemplo bastante ilustrativo pois mostra que somente uma biblioteca na classe A foi suficiente para conduzir os métodos tradicionais a uma resposta completamente insatisfatória. Existem muitos outros casos como esse, inclusive quando a explicação para a falha dos métodos tradicionais não pode ser atribuída a uma única biblioteca de comportamento discrepante. Todos os resultados deste tipo de análise para todas as tags estão disponíveis no web-site suplementar.

Tabela 2 - Tags diferencialmente expressas entre os tumores

\begin{tabular}{|l|l|l|c|}
\hline \multicolumn{1}{|c|}{ Tag } & \multicolumn{1}{c|}{ Gene } & \multicolumn{1}{c|}{ Anotação do gene } & $E$ \\
\hline GGCTGATGTG & GARS & glicil-tRNA sintetase & 0.00 \\
\hline GTGCTGGAGA & SNRPD2 & $\begin{array}{l}\text { ribonucleoproteina nuclear pequena D2 polipeptídeo } \\
16.5 \mathrm{kDa}\end{array}$ & 0.00 \\
\hline CAGCTCACTG & RPL14 & proténa ribossomal L14 & 0.00 \\
\hline TTCTATAAGC & RAP80 & proteína associada à receptor 80 & 0.00 \\
\hline GACACTACAC & P8 & proteína p8 (candidata de metastase 1) & 0.00 \\
\hline TCTCCTCCCA & Hs.282395 & seqüência transcrita & 0.00 \\
\hline TTAATATGTG & CRYL1 & cristalina 11 & 0.00 \\
\hline GATTTCTATT & Hs.288232 & CDNA: FLJ22642 fis, clone HSI06970 & 0.00 \\
\hline GGCCCCGCTT & C1orf17 & open reading frame 17 do cromossomo I & 0.00 \\
\hline CCAACCGTGC & GLO1 & glioxalase I & 0.00 \\
\hline TCCAGGAAAC & CTSF & catepsina F & 0.01 \\
\hline ATTCAATAAA & NAV2 & neuron navigator 2 & 0.01 \\
\hline TGTTTTTATG & PCBD & $\begin{array}{l}\text { 6-piruvoil-tetrahidropterin sintase / cofator de dimerização } \\
\text { de fator nuclear de hepatócito 1 } \alpha\end{array}$ & 0.01 \\
\hline AGATAGTTTA & C5orf11 & open reading frame 11 do cromossomo V & 0.01 \\
\hline TTAAGATCTT & D4S234E & $\begin{array}{l}\text { seqüência expressa 234 de segmento de DNA no } \\
\text { cromossomo IV }\end{array}$ & 0.01 \\
\hline AGTAGTATGA & FGF2 & fator de crescimeto de fibroblasto (básico) & 0.01 \\
\hline GCCAAAGTGT & RDH14 & retinol dehidrogenase 14 (todos -trans e 9-cis) & 0.01 \\
\hline GTTTATGGAT & MGP & proteína Gla da matriz & 0.01 \\
\hline AAAGTCTAGA & CCND1 & ciclina D1 (PRAD1: paratiroide adenomatose 1) & 0.01 \\
\hline GTCAAATGGT & Hs.445940 & seqüência transcrita & 0.01 \\
\hline
\end{tabular}

Neste exemplo consideramos como diferencialmente expressas as tags que resultaram num Bayes Error Rate, arbitrariamente definido, $E$ $\leq 0.01$, isto é, com um erro de classificação menor que $1 \%$ o que implica em fdps Beta intuitivamente bem separadas semelhantes à Fig. 9. 
A Tabela 2 lista os genes considerados diferencialmente expressos pelo nosso método e critérios, bem como os $P$-valores obtidos com os outros métodos. Entretanto, vale ressaltar que não é nosso objetivo nesta Dissertação, por estar fora do escopo de nossa competência científica, fazer a análise do ponto de vista Biológico apesar de sabermos que este problema prático tomado como exemplo de aplicação é um problema possivelmente relevante. 


\section{Capítulo 6}

\section{Conclusões}

Neste trabalho, o objetivo foi fornecer um guia para o atual estadoda-arte dos métodos estatísticos utilizados na análise de dados de Expressão Gênica obtidos com a técnica de Serial Analysis of Gene Expression (SAGE).

Delineamos alguns do problemas, inclusive alguns ainda em aberto, pois nos concentramos no problema de detecção de expressão diferencial, mas esperamos que as idéias principais sejam úteis para ajudar a seguir os trabalhos originais na literatura. Entretanto, demos bastante ênfase aos dos dois métodos originais desenvolvidos por nosso grupo de pesquisa no decorrer deste Projeto de Mestrado:

- SAGEci (www.vision.ime.usp.br/ rvencio/SAGEci), um método para construção de intervalos de credibilidade, ou informalmente barras-de-erro, para as razões de expressão de um transcrito (Vêncio et al., 2003) e;

- SAGEßBin (www.vision.ime.usp.br/ rvencio/SAGEbetaBin), um método para detectar expressão diferencial levando em conta a variabilidade biológica intra-classe das bibliotecas (Vêncio et al., 2004).

Na revisão bibliográfica, mostramos que a estimação da abundância pode ser mais elaborada do que a simples divisão da contagem de ocorrências de uma tag pelo total de seqüenciadas, mas por outro lado, pode receber um tratamento sofisticado como: a estimação multinomial, a correção de potenciais erros de seqüenciamento, incorporação de conhecimento a priori, e assim por diante.

Dado um conjunto de dados (supostamente) corrigido de erros sistemáticos, é preciso procurar por tags diferencialmente expressas entre as condições. Vários métodos para este fim foram apresentados, mas nós enfatizamos a importância do uso de desenhos experimentais contendo réplicas biológicas para capturar uma informação com maior poder de generalização.

Finalmente, queremos salientar que somente o acúmulo de dados experimentais em bancos-de-dados públicos, com replicas biológicas, e o uso de boa Estatística podem aumentar a utilidade dos dados de contagem vindos de SAGE, MPSS ou ESTs em termos gerais, ajudando 
a elucidar questões básicas e aplicadas nesta área tão importante da Biologia Molecular moderna que é a Expressão Gênica. 


\section{Bibliografia}

Akmaev, V.R. \& Clarence J. Wang, C.J. (2004) Correction of sequence based artifacts in serial analysis of gene expression. Bioinformatics (no prelo).

Audic S. \& Claverie J. (1997) The significance of digital gene expression profiles. Genome Research 7, 986-995.

Baggerly, K.A., Deng, L., Morris, J.S. \& Aldaz, C.M. (2003) Differential expression in SAGE: accounting for normal between-library variation. Bioinformatics 19, 1477-83.

Blades, N., Velculescu, V.E \& Parmigiani, G. (2004) Estimation of sequencing error rates in SAGE libraries. Genome Biology (no prelo).

Blades, N., Jones, J.B., Kern, S.E. \& Parmigiani, G. (2004) Denoising of data from serial analysis of gene expression. Bioinformatics (no prelo).

Boon, K., Osório, E.C., Greenhut, S.F., Schaefer, C.F., Shoemaker, J., Polyak, K., Morin, P.J., Buetow, K.H., Strausberg, R.L., Souza, S.J. \& Riggins, G.J. (2002) An anatomy of normal and malignant gene expression. Proc. Natl. Acad. Sci. USA 99, 11287-11292.

Brenner, S., Johnson, M., Bridgham, J., et al. (2000) Gene expression analysis by massively parallel signature sequencing (MPSS) on microbead arrays. Nature Biotechnology 18, 630-634.

Chen, H., Centola, M., Altschul, S.F. \& Metzger H. (1998) Characterization of gene expression in resting and activated mast cells. J. Exp. Med 188, 1657-1668.

Colinge, J. \& Feger, G. (2001) Detecting the impact of sequencing errors on SAGE data. Bioinformatics 17, 840-842.

Ewing, B. \& Green, P. (1998) Base-calling of automated sequencer traces using phred. II. error probabilities. Genome Research 8, 186194.

Greller, L.D. \& Tobin, F.L. (1999) Detecting selective expression of genes and proteins. Genome Research 9, 282-296.

Ihaka, R. \& Gentleman, R. (1996) R: A language for data analysis and graphics. Journal of Computational and Graphical Statistics 5, 299314.

Jeffreys, H. (1961) in Theory of Probability, (Oxford University Press).

Kal, A.J., van Zonneveld, A.J., Benes, V., van den Berg, M., Koerkamp, M.G., Albermann, K., Strack, N., Ruijter, J.M., Richter, A., Dujon, B., Ansorge, W. \& Tabak, H.F. (1999) Dynamics of gene expression revealed by comparison of serial analysis of gene expression 
transcript profiles from yeast grown on two different carbon sources. Mol. Biol. Cell 10, 1859-1872.

Lal, A., Lash, A.E., Altschul, S.F., Velculescu, V., Zhang, L., McLendon, R.E., Marra, M.A., Prange, C., Morin, P.J., Polyak, K., Papadopoulos, N., Vogelstein, B., Kinzler, K.W., Strausberg, R.L. \& Riggins, G.J. (1999) A public database for gene expression in human cancers. Cancer Research 21, 5403-5407.

Lash, A.E., Tolstoshev, C.M., Wagner, L., Schuler, G.D., Strausberg, R.L., Riggins, G.J. \& Altschul, S.F. (2000) SAGEmap: a public gene expression resource. Genome Research 10, 1051-1060.

Man, M.Z., Wang X. \& Wang Y. (2000) POWER_SAGE: comparing statistical tests for SAGE experiments. Bioinfomatics 16, 953-959.

Margulies, E.H., Kardia, S.L. \& Innis, J.W. (2001) Identification and prevention of a GC content bias in SAGE libraries. Nucleic Acids Res. 29, e60.

Morris, J.S., Baggerly, K.A. \& Coombes, K.R. (2003) Bayesian shrinkage estimation of the relative abundance of mRNA transcripts using SAGE. Biometrics 59, 476-486.

Romualdi, C., Bortoluzzi, S. and Danieli, G.A. (2001) Detecting differentially expressed genes in multiple tag sampling experiments: comparative evaluation of statistical tests. Human Molecular Genetics 10, 2133-2141.

Ruijter, J.M., Kampen, A.H.C. \& Baas F. (2002) Statistical evaluation of SAGE libraries: consequences for experimental design. Physiol Genomics 11, 37-44.

Schuler, G.D. (1997) Pieces of the puzzle: expressed sequence tags and the catalog of human genes. J. Mol. Med. 75, 694-698.

Stekel, D.J., Git, Y. \& Falciani, F. (2000) The comparison of gene expression from multiple cDNA libraries. Genome Research 10, 20552061.

Stern, M.D., Anisimov, S.V. \& Boheler, K.R. (2003) Can transcriptome size be estimated from SAGE catalogs?. Bioinformatics 19, 443-448.

Stollberg, J., Urschitz, J., Urban, Z. \& Boyd, C.D. (2000) A Quantitative Evaluation of SAGE. Genome Research 10, 1241-1248.

Venables, W. N. \& Ripley, B. D. (1999) in Modern Applied Statistics with S-PLUS, (Springer Press).

Vêncio, R.Z.N., Brentani H. \& Pereira, C.A.B. (2003) Using credibility intervals instead of hypothesis tests in SAGE analysis. Bioinformatics 19, 2461-2464. 
Vêncio, R.Z.N., Brentani, H., Patrão, D.F.C. \& Pereira, C.A.B. (2004) Bayesian model accounting for within-class biological variability in Serial Analysis of Gene Expression (SAGE). BMC Bioinformatics 5, 119.

Velculescu, V.E., Zhang, L., Vogelstein, B. \& Kinzler, K.W. (1995) Serial analysis of gene expression. Science 270, 484-487.

Velculescu, V.E., Zhang, L., Zhou, W., Vogelstein, J., Basrai M.A., Bassett, D.E., Hieter, P., Vogelstein, B. \& Kinzler, K.W. (1997) Characterization of the yeast transcriptome. Cell 88, 243-251.

Watson, J.D. \& Crick, F.H.C. (1953) Molecular structure of nucleic acids. Nature 171, 737-738.

Zhang, L., Zhou, W., Velculescu, V.E., Kern, S.E., Hruban, R.H., Hamilton, S.R., Vogelstein, B., \& Kinzler, K.W. (1997) Gene Expression Profiles in Normal and Cancer Cells. Science 276, 1268 1272. 